\title{
Molecular Basis of the Brain Renin Angiotensin System in Cardiovascular and Neurologic Disorders: Uncovering a Key Role for the Astroglial Angiotensin Type 1 Receptor AT1R
}

\author{
Dhanush Haspula and Michelle A. Clark \\ Department of Biomedical Engineering, Medical College of Wisconsin, Milwaukee, Wisconsin (D.H.); and College of Pharmacy, \\ Department of Pharmaceutical Sciences, Nova Southeastern University, Ft. Lauderdale, Florida (M.A.C.)
}

Received February 28, 2018; accepted May 8, 2018

\begin{abstract}
The central renin angiotensin system (RAS) is one of the most widely investigated cardiovascular systems in the brain. It is implicated in a myriad of cardiovascular diseases. However, studies from the last decade have identified its involvement in several neurologic abnormalities. Understanding the molecular functionality of the various RAS components can thus provide considerable insight into the phenotypic differences and mechanistic drivers of not just cardiovascular but also neurologic disorders. Since activation of one of its primary receptors, the angiotensin type 1 receptor (AT1R), results in an augmentation of oxidative stress and inflammatory cytokines, it becomes
\end{abstract}

essential to investigate not just neuronal RAS but glial RAS as well. Glial cells are key homeostatic regulators in the brain and are critical players in the resolution of overt oxidative stress and neuroinflammation. Designing better and effective therapeutic strategies that target the brain RAS could well hinge on understanding the molecular basis of both neuronal and glial RAS. This review provides a comprehensive overview of the major studies that have investigated the mechanisms and regulation of the brain RAS, and it also provides insight into the potential role of glial AT1Rs in the pathophysiology of cardiovascular and neurologic disorders.

\section{Introduction}

The renin angiotensin system (RAS) is a cardioregulatory, peptidergic, hormonal system that is involved primarily in the regulation of blood pressure. Its pivotal function is to elevate blood pressure in hypotensive states. In response to a drop in blood pressure, low salt concentration, or low blood volume, the juxtaglomerular apparatus in the kidneys triggers the RAS cascade, which ultimately culminates in a significant antinatriuretic, antidiuretic, and vasoconstrictive effect (Hall, 1986; Montani and Van Vliet, 2004). Components of the RAS, as will be discussed in the succeeding sections, are found in virtually every organ/tissue of the body. Hence, their functions go beyond regulation of blood pressure. Of significant interest

This work was supported by Nova Southeastern University [President's Faculty Research and Development Grant 335309 and Health Professions Division Grant 335585].

https://doi.org/10.1124/jpet.118.248831. is the action of the RAS in the brain. An overactive brain RAS has been demonstrated to be a characteristic feature of multiple cardiovascular diseases. However, evidence shows that the underlying pathologic mechanisms of the RAS can be extrapolated to several neurologic disorders as well. An increase in oxidative stress, proinflammatory mediators, and a decrease in anti-inflammatory cytokines are tightly intertwined with the progression of both cardiovascular and neurologic disorders. The RAS plays a pivotal role in controlling these drivers of cardiovascular and neurologic disorders.

\section{Classic and Nonclassic RAS and Therapeutic Interventions}

The RAS is composed of several different components that encompass precursor and active peptides, enzymes, and receptors. Renin, secreted from the kidneys, converts angiotensinogen (AGT), secreted from the liver, to angiotensin

ABBREVIATIONS: ACE, angiotensin-converting enzyme; ACEI, angiotensin-converting enzyme inhibitor; ADHD, attention deficit hyperactive disorder; AGT, angiotensinogen; Ang, angiotensin; ARB, angiotensin receptor blocker; AT1R, angiotensin type 1 receptor; AT2R, angiotensin type 2 receptor; AT4R, angiotensin type 4 receptor; C21, compound 21; ERK, extracellular signal-regulated kinase; GPCR, G protein-coupled receptor; IL, interleukin; MAPK, mitogen-activated protein kinase; MS, multiple sclerosis; NF- $\kappa$ B, nuclear factor $\kappa \mathrm{B}$; NO, nitric oxide; NOS, nitric oxide synthase; NTS, nucleus of the solitary tract; PI3K, phosphoinositide 3-kinase; PVN, paraventricular nucleus; RAS, renin angiotensin system; ROS, reactive oxygen synthase; RVLM, rostral ventrolateral medulla; SFO, subfornical organ; SHR, spontaneously hypertensive rat; SON, supraoptic nucleus; WKY, Wistar Kyoto. 
(Ang) I. Ang I is converted into Ang II by the action of the angiotensin-converting enzyme (ACE), an enzyme produced in the lungs and blood vessels (Montani and Van Vliet, 2004). It is now widely accepted that Ang II is secreted by a diverse group of cell types, and its source is not restricted to only liver AGT (Ganong, 1994; Paul et al., 2006). The former is part of the local RAS, whereas the latter constitutes the systemic RAS. Optimal functioning of both the systemic and local RAS is critical for overall cardiovascular homeostasis (Lavoie and Sigmund, 2003). Ang II, the major effector peptide of the RAS, is a circulating hormone that has a major physiologic and pathophysiological bearing on cardiovascular functions. Although most of their functions converge to have one singular outcome (i.e., an elevation in blood pressure), the RAS also has a role in digestion, reproduction, and prenatal development (Paul et al., 2006).

The widely studied and documented actions of Ang II, such as aldosterone secretion and its vasoconstrictive and ionotropic effects, are due to its ability to interact with the angiotensin type 1 receptor (AT1R) (Fyhrquist et al., 1995). Ang II couples with AT1R, a pertussis toxin-insensitive G protein-coupled receptor (GPCR), to produce a spike in calcium levels. Elevations in calcium activate kinases, signaling pathways, and transcription factors and consequently cause several physiologic actions such as smooth muscle contraction and aldosterone synthesis (de Gasparo et al., 2000). By interacting with AT1R on renal, cardiac, and vascular cells, Ang II is able to increase aldosterone levels, elevate salt intake, cause sympathetic nervous system hyperactivation, have a positive ionotropic effect, and elicit potent vasoconstriction (Fyhrquist et al., 1995). Ang II also interacts with the angiotensin type 2 receptor (AT2R), which is known to elicit functions that are antagonistic to AT1R, such as a reduction of oxidative stress and neutralizing proinflammatory states (Stoll et al., 1995; Namsolleck et al., 2014). At a physiologic level, AT2R activation results in vasodilatory and cardioprotective effects ( $\mathrm{Li}$ et al., 2012).

Several other RAS peptides that are both functionally similar and dissimilar to Ang II have also been identified, characterized, and studied (Paul et al., 2006). Ang III, Ang IV, and Ang (1-7) are physiologically active degradation products of Ang II. Ang III interacts with AT1R, whereas Ang IV and Ang (1-7) interact with their own cognate receptors, the Ang type 4 receptor (AT4R) and the Mas receptor, respectively (Varagic et al., 2008). Ang II is degraded by aminopeptidases to Ang III and Ang IV and by ACE2 to Ang (1-7) (Paul et al., 2006). Alternatively, Ang (1-7) can also be synthesized from Ang I by the action of neprilysin (Paul et al., 2006). Ang III exhibits functional similarity to Ang II, whereas Ang (1-7) counteracts the deleterious effects of Ang II (Ferrario et al., 1991). Owing to the anti-inflammatory and antioxidant properties of the Mas receptor, Ang (1-7) has been demonstrated to have potent cardioprotective and neuroprotective properties (Bennion et al., 2015). Ang IV also has cardioprotective and neuroprotective effects. Ang IV is not only known to elicit potent vasodilatory effects (Kramár et al., 1997; Hamilton et al., 2001), but it has also been demonstrated to diminish the production of several proinflammatory cytokines (Kong et al., 2015). Ang IV receptor activation is linked to an improvement in cognitive abilities such as learning and memory, and it has been suggested as a potential therapeutic target for Alzheimer disease (Wright and Harding, 2008; Royea et al., 2017).
Although a dysregulated RAS is one of the hallmarks of cardiovascular diseases (Veerasingham and Raizada, 2003), its functions are fundamental for survival under physiologic conditions. Through multiple mechanisms, Ang II controls and maintains blood pressure and blood volume within set boundaries. Although vasoconstriction is often viewed as its major mechanism, its ability to increase water retention and elevate sympathetic activity makes it a powerful and unique system in understanding the pathophysiology of cardiovascular diseases. Ang II-mediated hypertrophy and hyperplasia are characteristic features of multiple risk factors of cardiovascular diseases, such as hypertension and diabetes (Fyhrquist et al., 1995). Owing to the ubiquitous nature of AT1R expression in the body, overactivity of AT1R is linked to multiple organ and tissue dysfunctions. Ang II is a well established mitogen that is known to trigger hypertrophy and cell migration via AT1R activation (Ushio-Fukai et al., 1996; Takeuchi et al., 2006; Lee et al., 2007; Campos et al., 2012). Cardiac hypertrophy, renal disease, and endothelial dysfunction have all been demonstrated to have an augmented RAS component. Since both Ang II synthesis and AT1R activity are fundamental to RASmediated elevation in blood pressure, drugs that impede synthesis of Ang II, or those that antagonize the deleterious effects of AT1Rs, are the mainstays in the pharmacological management of numerous cardiovascular diseases, their risk factors, and their complications (Burnier and Zanchi, 2006; Atlas, 2007). In addition to its augmented ability to elevate blood pressure by multiple mechanisms in pathologic conditions, Ang II can also cause extensive damage to the heart, kidneys, and vasculature (Long et al., 2004; Montezano et al., 2014; Wang et al., 2014). For example, AT1R angiotensin receptor blockers (ARBs) and angiotensin-converting enzyme inhibitors (ACEIs) are routinely employed in the management of heart failure (Aranda and Conti, 2003; Atlas, 2007).

An alternative strategy is to counteract the effects of AT1R by activating receptors and systems that exhibit functional antagonism to the receptor. In this regard, several groups have explored the therapeutic potential of AT2R agonists, which exhibit vasodilatory and cardioprotective effects such as a reduction in inflammation and fibrosis as well as cause prooxidant states (Danyel et al., 2013; Matavelli and Siragy, 2015). Although AT2R activation has been shown to result in significant vasodilation, the AT2R agonist compound 21 (C21) did not alter blood pressure when administered alone in hypertensive and nonhypertensive rats (Carey et al., 2001; Bosnyak et al., 2010). C21 caused a significant reduction only in the presence of AT1R blockers. Owing to the relatively low expression of AT2Rs compared with AT1Rs, it could be that the AT1R tone is far greater than AT2R-mediated vasorelaxation under baseline conditions. In addition, the Ang (1-7)-ACE2-Mas axis has also been viewed as a potential therapeutic target to negate the deleterious effects of AT1R activation. Several in vitro and in vivo studies have demonstrated a significant protective role for this pathway in cardiac tissue under pathologic conditions (Zhong et al., 2010; Patel et al., 2012). The ability of Ang (1-7) to improve not only endothelial and vascular function (Sampaio et al., 2007; McKinney et al., 2014) but also the metabolic panel and to serve as a renoprotectant in diabetic states (Mori et al., 2014a,b) makes the Mas receptor an attractive druggable target. The schematic representation of the RAS pathway and the role of its receptors in regulation of cardiovascular functions is shown in Fig. 1. 


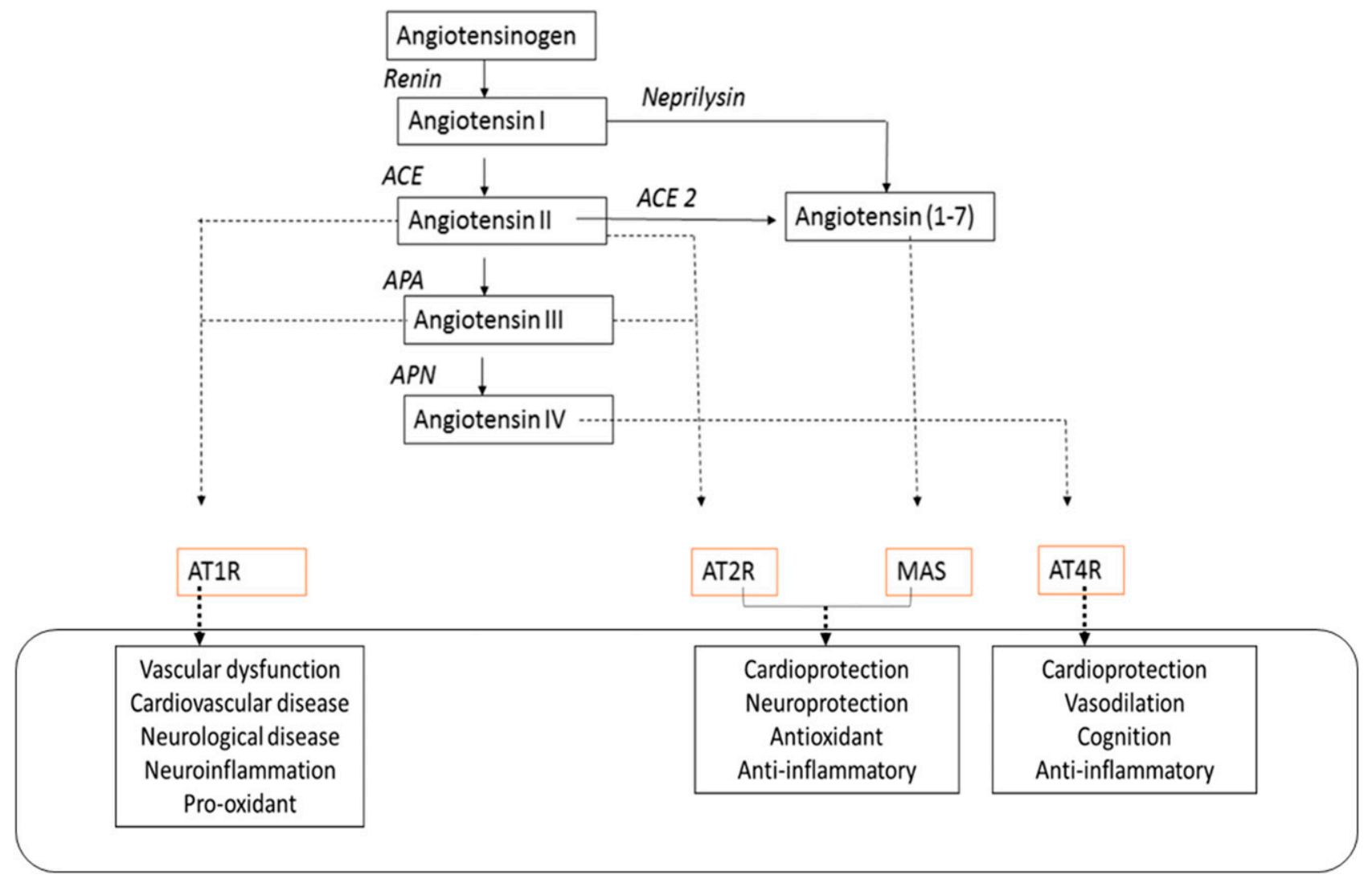

Fig. 1. The RAS pathway and the role of its receptors in the regulation of cardiovascular functions. AGT is the precursor protein for the synthesis of the major Ang peptides. The actions of these peptides are mediated by the four receptors listed. APA, aminopeptidase A; APN, aminopeptidase N.

Crosstalk between different components of the RAS has also been reported. For instance, Ang II has been shown to upregulate ACE and downregulate ACE2 in kidney cells and neuronal cells (Koka et al., 2008; Xiao et al., 2013). Receptors belonging to RAS and also other molecular systems are known to negatively or positively regulate AT1R activity by several different modes of crosstalk. For instance, AT2R has been demonstrated to cause heterologous desensitization of AT1R through a protein kinase C-dependent mechanism and thus diminish its activity in transfected cells (Inuzuka et al., 2016). Interestingly, AT1R activity was reduced in the amygdala of mice brains that lacked the MAS receptor, further highlighting the crosstalk among the various components of the RAS (Von Bohlen und Halbach et al., 2000). Interestingly, a subpressor dose of Ang II has a similar angiogenic response to a low dose of Ang (1-7), further highlighting the complex interplay between various components of the RAS (Hoffmann et al., 2017). Although the cannabinoid type 1 receptor has been demonstrated to potentiate AT1R profibrinogenic activity by way of heterodimerization (Rozenfeld et al., 2011), it has also has been demonstrated to diminish AT1R's ability to activate key signaling pathways in astrocytes (Haspula and Clark, 2017b). In addition, receptor interactions with adrenergic receptors also enable drugs such as $\beta$-blockers to influence AT1R activity (Barki-Harrington et al., 2003). Heterodimers between AT2R and MAS have been shown to be functionally relevant in astrocytes, whereby knockout of either of the receptors led to a diminished functionality of the other (Leonhardt et al., 2017).
Although AT1R is considered to be a prototypical plasma membrane receptor, evidence of Ang II binding sites that are localized intracellularly and bear similarity with AT1R has been reported in various tissues such as the liver (Booz et al., 1992; Tang et al., 1992). Evidence of an intracellular RAS in the brain comes from studies on a nonsecretory variant of renin that retains its enzymatic activity (Lee-Kirsch et al., 1999) and was also shown to modulate thirst and blood pressure in transgenic animals (Lavoie et al., 2006). In neurons, Ang receptors were recently identified on nuclei as well as on other organelles such as mitochondria, where they have a role in neuroprotection and respiration (Valenzuela et al., 2016; Villar-Cheda et al., 2017). It becomes important to understand the functional significance of intracellular binding sites for Ang II in brain cells such as astrocytes, since it was shown in cardiomyocytes that Ang II performed functions intracellularly that are different from those of extracellular Ang II (De Mello, 2008).

\section{Brain RAS and Blood Pressure Control}

Studies on borderline hypertensive humans and hypertensive animal models have confirmed the importance of an augmented central sympathetic activity in the pathogenesis of hypertension (Anderson et al., 1989; Korner et al., 1993; Fisher et al., 2009; Fisher and Paton, 2012). This has also led to the inception of the neuroadrenergic hypothesis for hypertension put forth by Grassi et al. (2010), which underscored the role of sympathetic hyperactivity in triggering and 
in perpetuating hypertensive conditions. Cardiovascular centers in the brainstem, rostral ventrolateral medulla (RVLM), and nucleus of the solitary tract (NTS) and in the hypothalamus and paraventricular nucleus (PVN) serve as both important convergence and divergence points for the regulation of blood pressure. Studies in hypertensive rat models characterized by an augmented sympathetic tone have revealed a dysfunction in cardiovascular centers (Allen, 2002; Ito et al., 2002). In addition, several other nuclei such as the subfornical organ (SFO), parabrachial nucleus, organum vasculosum of the lamina terminalis, and supraoptic nucleus (SON) also play a vital role in regulation of cardiovascular function.

Understanding the significance of the brain RAS is vital, since its augmentation has been reported and implicated in several cardiovascular diseases and conditions (Veerasingham and Raizada, 2003; Huang and Leenen, 2009; Campos et al., 2012). Although functional AT1Rs in the brain were identified in the 1960s (Bickerton and Buckley, 1961), the notion that brain cells could produce Ang II was suggested much later. Evidence of Ang II-synthesizing enzymes and Ang II precursors in brain cells provided the early foundation for the conception of an independently functioning brain RAS (Brooks and Malvin, 1979; Phillips, 1983; Campbell et al., 1984). In the central nervous system, AT1R levels are particularly greater in the cardiovascular centers of the hypothalamus and brainstem, further highlighting the importance of the RAS in the regulation of cardiovascular parameters (Phillips et al., 1993; Lenkei et al., 1995; Hu et al., 2002). Ang II, a potent dipsogen, can increase water intake by activating AT1Rs in the SFO, SON, and organum vasculosum of the lamina terminalis (Simpson et al., 1978; Qadri et al., 1993; Morris et al., 2002; Coble et al., 2014).

In addition, brain Ang II also has critical neuromodulatory functions, whereby it activates neuronal AT1Rs to alter synaptic strength and activity by modulating impulses generated by several neurotransmitters such as glutamate, GABA, and norepinephrine (Tsuda, 2012). The PVN and RVLM cardiovascular centers are especially critical for Ang II-mediated sympathoexcitation. By disinhibiting GABAergic neurons in the PVN, Ang II is able to stimulate neurons projecting from the PVN to the RVLM, thereby facilitating an increase in sympathetic activity (Cato and Toney, 2005; Li and Pan, 2005). AT1Rs present in the cardioregulatory centers of the brainstem are known to not only attenuate baroreflex sensitivity but also increase firing rates of sympathetic neurons (Matsumura et al., 1998; Matsuura et al., 2002). Viral transfection of a constitutively active form of the AT1R into the RVLM caused a spike in blood pressure (Allen et al., 2006), whereas inhibiting it resulted in a decrease in blood pressure in several animal models of hypertension (Ito et al., 2002; de Oliveira-Sales et al., 2010). These findings provide further evidence of its central role in hypertension. Ang II effects in the NTS, however, suggest a more complex mechanism of action. Low and high doses of Ang II elicited different responses, or even a lack of significant response, on blood pressure and heart rate regulation (Rettig et al., 1986; Mosqueda-Garcia et al., 1990; Paton and Kasparov, 1999). Ang II in the NTS was also shown to play a vital role in diminishing baroreflex sensitivity (Campagnole-Santos et al., 1988; Polson et al., 2007).
Further evidence for a role of brain RAS in cardiovascular disorders came from studies in spontaneously hypertensive rats (SHRs), widely regarded as the best model to study essential hypertension. The brain RAS was demonstrated to be overactive in SHRs compared with their normotensive controls (Veerasingham and Raizada, 2003; Haspula and Clark, 2018). AT1R levels were observed to be higher in the brainstems of SHRs compared with their normotensive controls, Wistar Kyoto (WKY) rats (Gutkind et al., 1988; Hu et al., 2002). RAS activity was demonstrated to be markedly potentiated in the cardioregulatory regions of the brainstem and hypothalamus of SHRs compared with their normotensive controls (Casto and Phillips, 1985; Matsuda et al., 1987; Gutkind et al., 1988; Muratani et al., 1991; Stadler et al., 1992; Zhu et al., 1998; Hu et al., 2002; Ito et al., 2002; Sun et al., 2009; Haspula and Clark, 2017b; Negussie et al., 2017). Both synthesis and turnover of Ang II were also enhanced in SHRs compared with their normotensive controls (Ganten et al., 1983; Hermann et al., 1984). An overview of studies that have reported an elevation in AT1R activity in the brainstems of SHRs is shown in Fig. 2.

Apart from AT1R, other components of the RAS were also observed to be altered in rodent models of hypertension. ACE2 levels were reported to be markedly lower in the hypothalamus of SHRs compared with WKY rats, resulting in an augmented ACE-Ang II-AT1R axis (Wang et al., 2017). AT2R activation was observed to have a greater antihypertensive effect in hypertensive models compared with normotensive models (de Kloet et al., 2017; Steckelings et al., 2017). Ang (1-7) was demonstrated to restore normal baroreflex functioning and autonomic activity in transgenic (mRen2)27 hypertensive rats (Kangussu et al., 2015). In response to hypoxia, often accompanied by an elevation in sympathetic activity, ACE levels were shown to be elevated in the median preoptic nucleus (Faulk et al., 2017). Brain AT2R activation can negate the sympathoexcitatory response that is a consequence of AT1R-mediated sympathoexcitation and also renal volume expansion (Stegbauer et al., 2005; Gao and Zucker, 2011; Abdulla and Johns, 2017). Increased blood pressure and attenuated baroreflex sensitivity in the offspring of betamethasone-exposed sheep was shown to be a consequence of central RAS impairment, which was improved by Ang (1-7) (Hendricks et al., 2017). Ang (1-7) also negated the Ang II-mediated chronotropic response in the hypothalamic neurons of prehypertensive SHRs (Modgil et al., 2012).

At a molecular level, several mechanisms such as endoplasmic reticulum stress, mitochondrial dysfunction, and redoxsensitive transcriptional factors have all been attributed to brain-derived Ang II promoting neurogenic hypertension and baroreflex impairment (Nautiyal et al., 2013; Coble et al., 2015; Young and Davisson, 2015; Case et al., 2017). An increase in reactive oxygen species (ROS) levels in the brainstem cardioregulatory centers is a crucial step by which Ang II is able to augment multiple cardiovascular parameters such as sympathetic tone, heart rate, and water intake (Zimmerman et al., 2002, 2004; Nozoe et al., 2008; Chan and Chan, 2012). In a model of renovascular hypertension, increased levels of both oxidative stress markers and AT1R levels in the PVN and RVLM were demonstrated to be significant contributors to sympathoexcitation and hypertension (Oliveira-Sales et al., 2009; de Oliveira-Sales et al., 2010). Although NADPH oxidase and the mitochondrial electron 


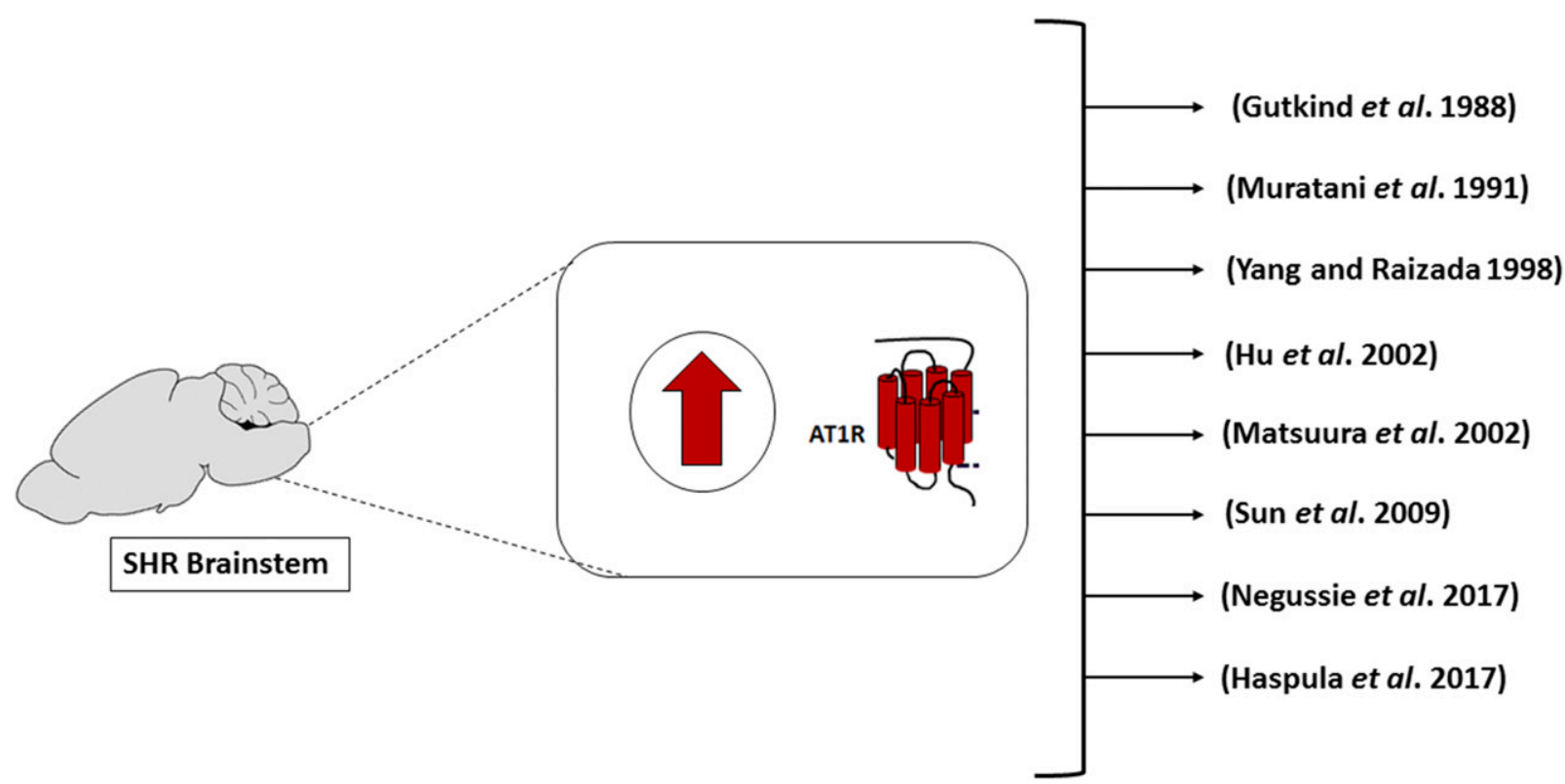

Fig. 2. An overview of studies reporting AT1R elevation in the brainstems of SHRs (Gutkind et al., 1988; Muratani et al., 1991; Yang and Raizada, 1998; Hu et al., 2002; Matsuura et al., 2002; Sun et al., 2009; Haspula and Clark, 2017b; Negussie et al., 2017).

transport chain serve as two potent sources of ROS, nitric oxide synthase (NOS) is also capable of generating ROS under a less stable and uncoupled state (Chan and Chan, 2012). The various NOS isoforms (endothelial, neuronal, and inducible NOS) were described as key mediators as well for Ang II effects on blood pressure and baroreflex gain (Paton et al., 2001; Cheng et al., 2010; de Oliveira-Sales et al., 2010). An increase in the levels of endothelial NOS, neuronal NOS, and inducible NOS was observed in the brainstem nuclei of hypertensive rats compared with their normotensive controls (Kishi et al., 2001; Edwards et al., 2004; Kimura et al., 2009; de Oliveira-Sales et al., 2010). Interestingly, nitric oxide (NO) levels were demonstrated to both neutralize (Zanzinger, 2002) as well as contribute to (Paton et al., 2001) Ang II-mediated elevation in ROS levels. Although a decrease in the levels of NO and NOS isoforms has been linked to sympathoexcitation, an increase in their levels has also been demonstrated to result in an increase in sympathetic activity (Chan et al., 2003; Hirooka et al., 2003). Losartan, an AT1R antagonist, reduced oxidative stress by acting on the mitochondrial electron transport chain (Sumbalová et al., 2010) as well as increasing levels of NO in the brainstem (Cheng et al., 2010). To add to the complexity of the sympathomodulatory role of the brainstem NOS, NOS activity was observed to be diminished under prehypertensive conditions but elevated under established hypertensive states (Qadri et al., 2003). A balance between the production of NO, ROS, and antioxidant levels is eminent for optimum regulation of sympathetic activity in the brainstem nuclei.

In addition to an elevation in ROS levels, various GPCR scaffold proteins, kinase signaling pathways, redoxdependent and independent transcription factors, ion channels, and tyrosine kinase receptors are also key players in brain AT1R-mediated pathologic effects (Shapiro et al., 1994; Yang et al., 1996; Huang et al., 1998; Zhu et al., 1999; Clark and Gonzalez, 2007; Agarwal et al., 2013; Xiao et al., 2013; Coble et al., 2014; Bali and Jaggi, 2016; Farag et al., 2017).
AT1R downregulation mediated by $\beta$-arrestin 1 overexpression in the SFO has been demonstrated to reduce blood pressure and sympathetic activity in SHRs compared with WKY rats (Sun et al., 2018). Dysfunctions of cardiovascular parameters in response to centrally administered Ang II have been demonstrated to occur through mitogen-activated protein kinase (MAPK)-dependent, as well as MAPKindependent, pathways such as phosphoinositide 3-kinase (PI3K) (Yang et al., 1996). PI3K has also been demonstrated to be crucial for Ang II-mediated depression of baroreflex function in the NTS of SHR brainstems (Sun et al., 2009). Although PI3K was demonstrated to be a critical mechanism for AT1R-mediated elevation of RVLM neuronal activity in SHRs compared with their normotensive controls (Seyedabadi et al., 2001; Veerasingham et al., 2005), extracellular signal-regulated kinase (ERK) $1 / 2$ was involved in Ang II-mediated inhibition of neuronal NOS activity (Cheng et al., 2010). Activation of ERK1/2 also plays a key role in the regulation of AT1R turnover in neuronal cultures (Yang et al., 1997). P38 MAPKs were shown to be involved in Ang II-mediated regulation of ACE and ACE2 activities in neuronal cells (Xiao et al., 2013). Both p38 and ERK MAPK pathways are also involved in Ang II-mediated activation of caspase 3 in RVLM neurons, the latter effect resulted in sympathoexcitation in the spontaneously hypertensive stroke-prone rat (Kishi et al., 2010). Transcription factors such as nuclear factor $\kappa \mathrm{B}(\mathrm{NF}-\kappa \mathrm{B})$ that are crucial to Ang II-mediated deleterious effects, such as an increase in the proinflammatory states in cells (Agarwal et al., 2013), are also responsible for AT1R-mediated homologous upregulation (Haack et al., 2013). The role of these intracellular mediators in glial cells is described in a later section.

RAS and catecholaminergic interactions are well established mechanisms by which central Ang II is capable of eliciting sympathoexcitation and dipsogenic effects (Gelband et al., 1998; Tsuda, 2012). Ang II has been shown to elevate both adrenaline (norepinephrine) release and uptake in brain 


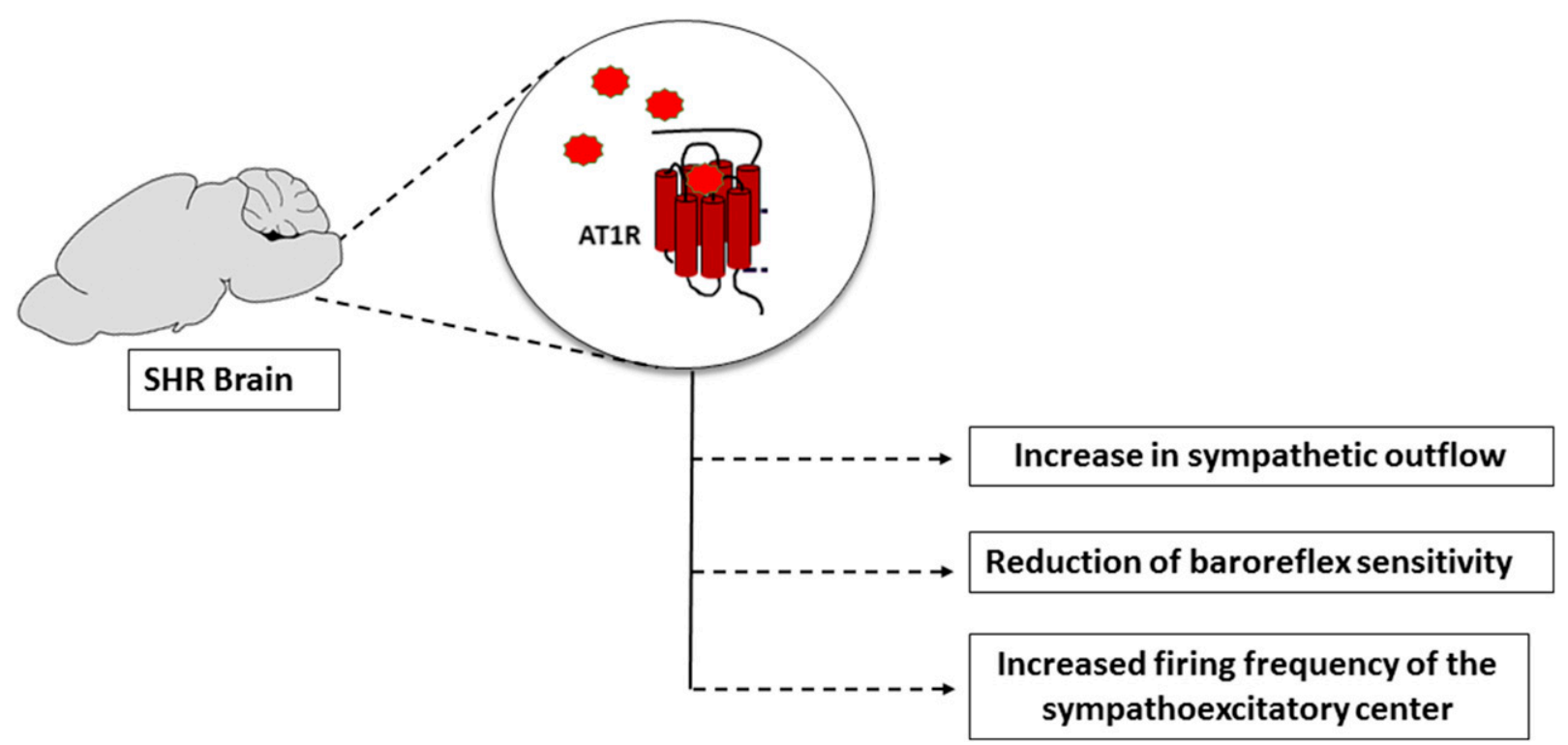

Fig. 3. An overview of the roles of brainstem AT1R in the regulation of cardiovascular parameters.

regions involved in the regulation of cardiovascular functions, and the latter functionality has also been shown to be elevated in SHR brain neurons (Qadri et al., 1991; Yang et al., 1996). In addition, Ang II via the AT1R and $\alpha$-adrenoreceptors in the SON has been shown to increase vasopressin release (Qadri et al., 1993). The dependence of Ang II on the mineralocoticoid receptor in mediating oxidative stress in the SFO has also been demonstrated (Wang et al., 2015). The effects of Ang II on other neurotransmitters and neuromodulators are mentioned in a subsequent section. An overview of the brainstem AT1R and its role in the regulation of various cardiovascular parameters is shown in Fig. 3.

\section{Significance of the Glial RAS in Cardiovascular Disease}

Overt excitatory impulses from the RVLM presympathetic neurons are ascribed as a major cause for sympathoexcitation that is observed in essential hypertension and cardiovascular diseases (Kumagai et al., 2012). Several theories have been attributed to this phenomenon. Imbalances in the levels of activating and restraining inputs to the RVLM (Smith and Barron, 1990; Ito et al., 2000), pro-oxidant and proinflammatory states in the RVLM (Wu et al., 2012), and imbalances between the excitatory and inhibitory neurotransmitters in the RVLM (Kishi et al., 2002) are some of the mechanisms that have been investigated. ATP is demonstrated to be an extremely important neurotransmitter in mediating the excitatory components of the RVLM (Marina et al., 2013) and the chemoreflex input of the NTS neurons (Braga et al., 2007). Purinergic signaling is a key signaling system that regulates cardiovascular function by exerting autonomic modulatory influences (Gourine et al., 2009). Purinergic signaling is also employed by astrocytes to communicate not only with other astrocytes but also with neurons (Fields and Burnstock, 2006). Brainstem hypoxia, which is commonly observed in hypertension and cardiovascular diseases, is also known to be a favorable environment for ATP release from astrocytes
(Marina et al., 2015, 2016). Using rat models of heart failure and hypertension, the roles of astroglial ATP were demonstrated to be exceedingly important in the pathogenesis of the aforementioned disorders (Marina et al., 2016).

Components of the RAS are expressed not only in neuronal cells but also in glial cells, and both of these brain cells have a role in regulating cardiovascular functions (Morimoto et al., 2002). Higher levels of AT1Rs were reported in neonatal rat astrocytes compared with neuronal cells (Sumners et al., 1991), highlighting the significance of astrocytes in mediating the effects of Ang II. Astrocytes are theorized to be the major source of AGT in the brain (Deschepper et al., 1986; Stornetta et al., 1988). In SHRs, an increase in the levels of AGT, prior to the development of hypertension, was identified in the brain (Tamura et al., 1996). Interestingly, our laboratory has demonstrated an increase in the levels of AGT from brainstem astrocytes in response to Ang II (Gowrisankar and Clark, 2016c). In addition, we observed an increase in ACE and a decrease in ACE2 in response to Ang II treatment (Gowrisankar and Clark, 2016b). Hence, the balance between the synthesizing and degradative enzymes could be altered, potentially favoring Ang II mobilization from astrocytes. This could explain the augmentation of RAS activity observed in the brainstems of SHRs.

Interestingly, neuroinflammatory cytokines were also reported to be elevated in the cardiovascular centers of the brainstem and hypothalamus (Agarwal et al., 2011). Not only do astrocytes and microglial cells have fundamental roles in the homeostatic regulation of cytokines in the brain, but cytokines themselves can influence glial cell functions (John et al., 2003). Impaired resolution of neuroinflammatory conditions could well lead to an impairment of cardioregulatory regions of the brain. In support of this view, SHRs treated with an inhibitor of S100 calcium-binding protein B, a proinflammatory and an apoptotic marker of astrocytes (Higashino et al., 2009), resulted in significant blood pressure reduction. Prominent astrogliosis was reported in SHRs by multiple groups, further highlighting the role of astrocytes in the pathogenesis of hypertension (Tomassoni et al., 2004). 
Although the importance of the astroglial RAS has been underscored by several studies, the molecular mechanisms underlying these effects have not yet been well investigated. Several groups have demonstrated the ability of proinflammatory cytokines to regulate sympathetic activity (Winklewski et al., 2015). The idea that a dysregulated neuroinflammatory state, in the cardiovascular centers of the brainstem, could contribute to sympathoexcitation was suggested by Paton and colleagues less than a decade ago (Waki et al., 2008). This was based on gene expression studies in the NTS of SHRs, where they observed altered inflammatory states, specifically in the levels of junctional adhesion molecule 1, monocyte chemotactic protein 1 , and interleukin (IL)-6 (Waki et al., 2008; Paton and Waki, 2009). Prominent neuroinflammatory states were observed at very early stages of hypertension in SHRs, indicating a causative factor in the pathogenesis of essential hypertension (Waki et al., 2008). Whether an increase in proinflammatory cytokines, in the cardiovascular centers of the brain, was an important mediator of Ang II-mediated sympathoexcitation was investigated by Kang et al. (2009). They demonstrated that chronic infusion of Ang II in Sprague-Dawley rats caused sympathoexcitation, which was characterized by a proinflammatory and a prooxidant state in the PVN. Blockade of AT1Rs and NF- $\kappa$ B was also demonstrated to normalize proinflammatory cytokines as well as sympathetic activity, further authenticating the role of neuroinflammation and the RAS in sympathoexcitation (Kang et al., 2009). Chronic infusion of Ang II resulting in a prominent inflammatory status in the brain vasculature was shown to occur via an increase in ROS levels (Zhang et al., 2010). Since glial cells play a critical role in the regulation of neuroinflammatory and oxidative states in the brain, glial AT1Rs could well be important factors in the augmentation of sympathetic activity. In support of this, ablation of astroglial AT1Rs in the brainstem has been demonstrated to result in an improvement in the symptoms of heart failure by normalization of sympathetic activity (Isegawa et al., 2014).

The link between the glial RAS, neuroinflammatory states, and sympathoexcitation was discussed in a review by Shi et al. (2010b). They conceptualized that glial AT1R activation results in an increase in the levels of proinflammatory cytokines, which can then act as neuromodulators of synaptic activity (Shi et al., 2010b). It is plausible that mobilization of cytokines from glial cells can alter neuronal activity, since low levels of cytokines can alter neuronal activity (Waki and Gouraud, 2014). Definitive evidence of the role of inflammatory cytokines and Ang II-mediated elevation in sympathetic nervous system activity came from studies in the hypothalamus by the same group (Shi et al., 2010a). Chronic Ang II infusion in the PVN resulted in an increase in proinflammatory cytokines and a decrease in antiinflammatory cytokines, which then caused an elevation in blood pressure (Shi et al., 2010a). This effect could be blocked by minocycline, indicating that this effect was mediated by microglial AT1Rs (Shi et al., 2010a). Circulating Ang II has also been shown to gain access to the cardiovascular centers in the brain by promoting blood-brain barrier breakdown (Vital et al., 2010; Biancardi and Stern, 2016). Both microglial AT1R-mediated elevation in oxidative stress and proinflammatory cytokines as well as molecular alterations in the brain microvasculature are viewed as the major mechanisms (Vital et al., 2010; Biancardi and Stern, 2016). Microglial cells were transformed predominantly into the M1 phenotype when exposed to Ang II, which represents a proinflammatory and a cytotoxic version of microglia, highlighting the role of microglial AT1Rs in promoting neuroinflammation and neurotoxicity (Rodriguez-Perez et al., 2016; Labandeira-Garcia et al., 2017). Further support came from another study investigating the crosstalk between the AT1R and Toll-like receptor 4 in the PVN. Ang II-mediated increases in ROS production were demonstrated to be due to an interaction between AT1R and Toll-like receptor 4 in microglial cells in the PVN (Biancardi et al., 2016). A synergistic effect on sympathetic activity has also been reported between proinflammatory cytokines and Ang II in the PVN (Shi et al., 2011). In addition to Ang II, other components of the RAS (e.g., prorenin) have also been highlighted as a potential inducer of neuroinflammation by microglial activation (Shi et al., 2014; Zhu et al., 2015). Interestingly, Ang (1-7) has not only been demonstrated to counteract the effects of prorenin, but it also induces microglial cells to assume an anti-inflammatory phenotype under basal conditions (Liu et al., 2016).

Microglial cell activation is often followed by astroglial activation in several neurologic disorders (Liu et al., 2011b). Hence, microglia may initiate the inflammatory response, and astrocytes may aid in perpetuating the proinflammatory states that have been reported in cardiovascular nuclei of the SHR brainstem and hypothalamus (Agarwal et al., 2011). Not just Ang II but other RAS peptides can also elicit proinflammatory states by interacting with the astroglial AT1R. PVN astrocytes isolated from SHRs, when treated with prorenin, resulted in an augmented increase in proinflammatory cytokines (Rodríguez et al., 2015). Ang III was also observed to have potent proinflammatory effects in normotensive brainstem astrocytes (Kandalam et al., 2015).

Our group observed an elevation of pro-oxidant and proinflammatory cytokines IL-1 and IL-6 in brainstem astrocytes, isolated from SHRs and Wistar rats, in response to Ang II treatment (Gowrisankar and Clark, 2016a; Haspula and Clark, 2017a). Baseline levels of the neuroinflammatory cytokines were also elevated in SHR brainstem astrocytes (Waki et al., 2008; Gowrisankar and Clark, 2016a; Haspula and Clark, 2017a). Interestingly, we observed an elevation in the levels of both pro- and anti-inflammatory cytokines in these cells (Haspula and Clark, 2017a). Since astrocytes are known to play a role in neutralizing oxidative stress and proinflammatory states, an increase in anti-inflammatory status could well be a compensatory/protective mechanism that needs to be further investigated. Studies from our laboratory have focused on uncovering the molecular pathways triggered by astroglial AT1R under hypertensive and normotensive conditions. Ang II via AT1R elevates ROS as well as activates key signal transduction pathways such as the ERK, p38, and Janus kinase/signal transducer and activator of transcription pathways. These are important systems that are critical to astroglial functions such as cell proliferation as well as to cardiovascular functions such as mobilization of inflammatory cytokines from astrocytes (Kandalam and Clark, 2010; Clark et al., 2013; Alanazi et al., 2014; Negussie et al., 2016; Haspula and Clark, 2017b).

\section{Brain RAS and Neurologic Disorders}

Higher prevalence rates of hypertension have been reported in neurologic impairments characterized by prominent neuroinflammation, such as cognitive decline (Skoog et al., 1996; 
Tzourio, 2007; Nelson et al., 2014; Muela et al., 2017). Some conflicting data exist relating to the correlation between hypertension and cognitive decline. Although some studies have shown a strong correlation between the two, others have shown no correlation or even a negative correlation (Morris et al., 2000; Qiu et al., 2003; Reitz et al., 2007; WarcholCelinska et al., 2015). Since activation of brain AT1Rs leads to an increase in proinflammatory and pro-oxidant states, it comes as little surprise that blockade of brain AT1Rs was investigated as a therapeutic strategy for several neurologic disorders (Wright et al., 2013; Mascolo et al., 2017). Evidence points to neutralization of the brain RAS as a treatment option in disorders pertaining to cognitive decline and memory loss (Mogi et al., 2012; Bodiga and Bodiga, 2013). Centrally acting ARBs were observed to have a greater efficacy than other antihypertensives in memory preservation in older hypertensive individuals (Ho and Nation, 2017). An observational casecontrol study assessing the efficacy of ACEIs on cognitive functions in elderly individuals also had favorable results (Gao et al., 2013). Furthermore, in a recently published study, an improvement in cognitive functions was observed with centrally acting ARBs in individuals diagnosed with $\mathrm{Alz}$ heimer disease (Fazal et al., 2017). ARBs also showed favorable neuropathological outcomes in hypertensive individuals with cognitive impairments (Hajjar et al., 2012). Considering that a strong correlation exists between cognitive decline and hypertension (Skoog et al., 1996; Tzourio, 2007; Nelson et al., 2014; Muela et al., 2017), hyperactivity of brain RAS, often associated with hypertension, could well be a hallmark of not only cardiovascular but also neurologic disorders as well.

An overactive brain RAS has also been linked to other neurodegenerative diseases such as Parkinson disease (Wright et al., 2013; Laudisio et al., 2017). In a prospective case-controlled study conducted on hypertensive individuals on ACEIs and ARBs, a reduced incidence of Parkinson disease was reported (Lee et al., 2014). In a recently published study, the ARB azilsartan was demonstrated to counteract apoptosis of dopaminergic neurons in a rat model of Parkinson disease (Gao et al., 2017). Telmisartan, an ARB that has peroxisome proliferator-activated receptor $\gamma$ activating ability, has been shown to reduce neuronal loss and inflammation in a mouse model of Alzheimer disease (Saavedra, 2012). Several preclinical studies have highlighted the role exogenous and endogenous Ang II in worsening Alzheimer disease pathophysiology, highlighting the potential deleterious role of AT1R in neurologic indices (Ongali et al., 2014; Takane et al., 2017). In addition to AT1R, other components of the RAS have also been shown to be altered in neurologic disorders. ACE2 activity was observed to be markedly reduced in the postmortem brain tissue of individuals diagnosed with Alzheimer disease (Kehoe et al., 2016). Prospective cohort analysis in males diagnosed with Alzheimer disease revealed a significant improvement in the progression of the disease in individuals taking ARBs compared with other cardiovascular drugs (Li et al., 2010). By employing animal models, the RAS has also been demonstrated to worsen autoimmune disorders such as multiple sclerosis (MS) by activating transforming growth factor $\beta$ (Lanz et al., 2010). Imbalances in cerebrospinal fluid Ang II levels, along with an impairment in perivascular astrocytes, were observed in patients with MS (Matsushita et al., 2010). Additionally, immunohistochemistry analysis revealed that plaques from the brains of patients with MS showed a strong upregulation in AT1R levels (Platten et al., 2009). Blocking of Ang II production was demonstrated to suppress the neuroinflammatory phenotype induced by activation of NF- $\kappa$ B via AT1R (Platten et al., 2009). Owing to the potential neuroprotective effect of ARBs, blocking of AT1R was shown to have promise in traumatic brain injury (Villapol et al., 2015). Since strong evidence exists linking centrally and noncentrally acting ACEIs or AT1R blockers with improvement of cognitive function, dementia, and neurodegeneration (Saxby et al., 2008; Mogi and Horiuchi, 2009; Davies et al., 2011), it is imperative that we understand and fully elucidate the mechanisms by which Ang II contributes to neuronal damage. Since astrocytes have a central role in brain homeostasis by regulating levels of cytokines and ROS, hyperfuctional astroglial AT1Rs may be a prominent feature of not only cardiovascular but also neurologic disorders.

Astrocytes from brain regions other than the brainstem, such as the cerebellum, are also responsive to Ang II treatment (Clark et al., 2013). Ang II caused a significant increase in the proinflammatory cytokine, IL-6, and ROS levels in astrocytes isolated from the cerebellum from both Wistar rats and SHRs (Gowrisankar and Clark, 2016a). Ang II-mediated ROS elevation and proinflammatory conditions are associated with neurodegeneration and also astrocyte senescence (Lanz et al., 2010; Liu et al., 2011a; Min et al., 2011). In addition, the SHR, which is characterized by a hyperactive brain RAS, is routinely employed as a model for attention deficit hyperactivity disorder (ADHD) (Adriani et al., 2003). Traits that are often observed in individuals with ADHD, such as shorter attention spans, inability to focus, and hyperexcitability, are also observed in the SHR, making it an ideal model to investigate the etiology of ADHD (Adriani et al., 2003). Similar to individuals with ADHD, SHRs are also characterized by cerebellar atrophy and cerebellar impairment (Yun et al., 2014). Evidence of a greater incidence of learning disabilities has also been reported in children with ADHD diagnosed with primary hypertension than in those without (Adams et al., 2010). These studies further highlight the importance of neuroinflammation in the pathogenesis of not only cardiovascular disorders but neurologic impairments as well. Considering that the RAS is a premium hormonal system that is augmented in the brains of SHRs, it is surprising to observe a paucity of studies investigating the effects of the RAS in ADHD. Nevertheless, the ability of Ang II to promote a proinflammatory state in different regions of the brain may lead to significant alteration in brain functions, eventually leading to neurologic disorders or an exacerbation of several neurologic conditions. A schematic of the potential role of glial AT1Rs in cardiovascular and neurologic diseases is shown in Fig. 4.

Exogenous administration of Ang II in the rat striatum was demonstrated to cause an increase in dopamine and serotonin metabolites, 3,4-dihydroxyphenylacetic acid and 5-hydroxyindoleacetic acid, respectively (Mendelsohn et al., 1993). A decrease in acetylcholine levels in the rat entorhinal cortex was also observed (Barnes et al., 1989), further highlighting the importance of the RAS in not only cardiovascular disorders but also neurologic disorders. Although AT1R is known to be associated with an increase in oxidative and inflammatory status, the role of AT2R in neuronal functions cannot be overlooked. The administration of both an AT2R agonist and an AT1R antagonist was shown to 


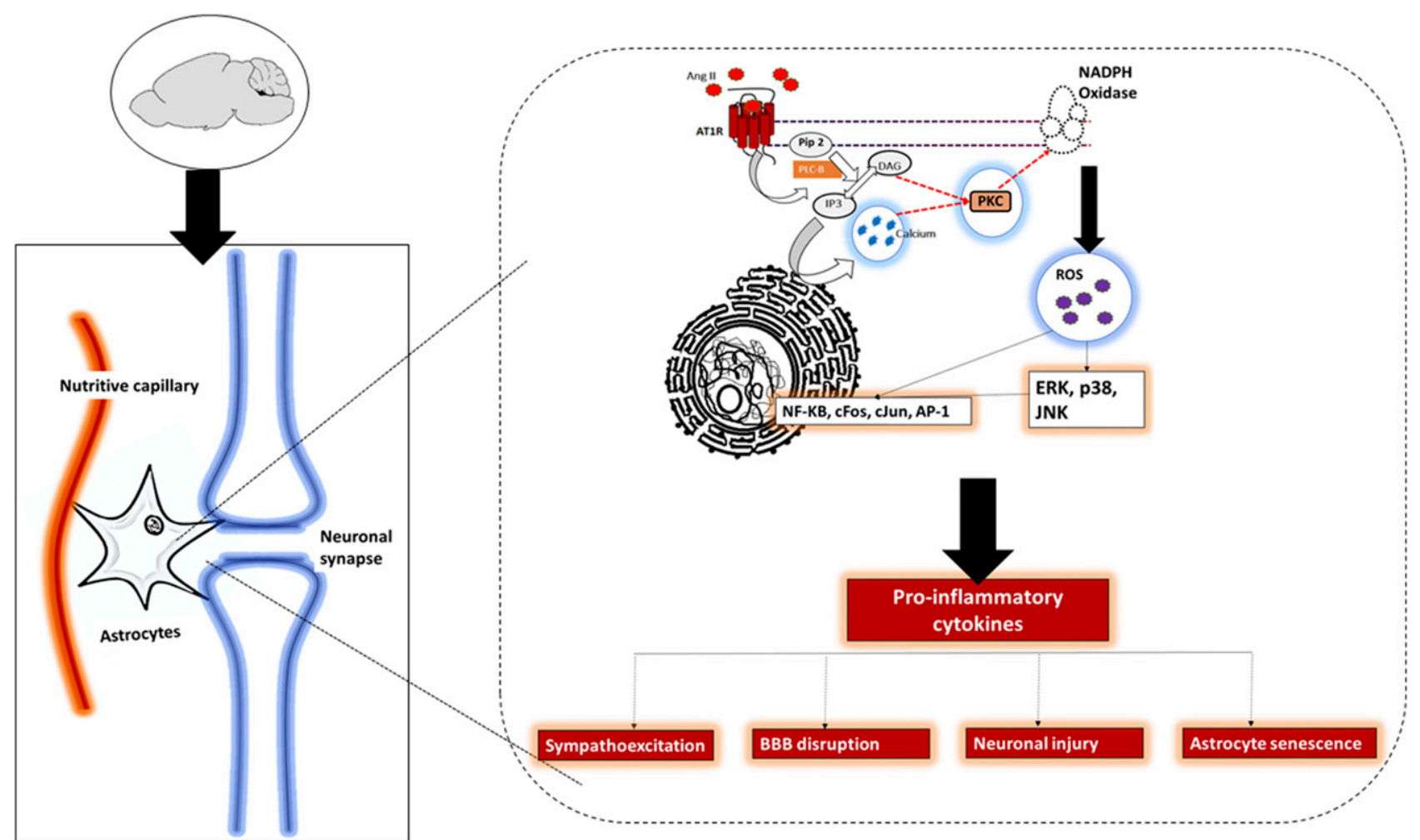

Fig. 4. A schematic of potential roles of astroglial AT1Rs in cardiovascular and neurologic diseases. Ang II activates AT1Rs leading to the stimulation of a host of intracellular mediators. These mediators lead to an increase in proinflammatory cytokines that can trigger a diverse array of events in the central nervous system. AP-1, activator protein-1; BBB, blood-brain barrier; DAG, diacylglycerol; IP3, inositol trisphosphate; JNK, Jun N-terminal kinase; PIP2, phosphatidylinositol biphosphate; PKC, protein kinase C; PLC, phospholipase C.

lower 3,4-dihydroxyphenylacetic acid levels (Mertens et al., 2010). Activation of AT2R has been reported to improve memory performance (Matavelli and Siragy, 2015) and to also confer neuroprotection in middle cerebral artery occlusion-induced stroke (Joseph et al., 2014; Min et al., 2014). The mechanisms could be due to its role in neuronal differentiation, excitability, regeneration, apoptosis, and reduction in oxidative stress and inflammation (Côté et al., 1999; Gendron et al., 2003; Min et al., 2014). AT2R is shown to be mostly expressed on neuronal cells and not glial cells (Bennion et al., 2017). It is mostly the neuronal AT2R that is responsible for the cerebroprotective effects conferred by AT2R agonism after middle cerebral artery occlusion-induced stroke (Bennion et al., 2017).

In addition to AT1Rs and AT2Rs, AT4R has also been identified to have a significant impact on cognition. Ang IV and other AT4R ligands have been shown to significantly improve several different facets of memory and learning performance in rats (Wright et al., 1993; Lee et al., 2004; Wright and Harding, 2008). An elevation in acetylcholine release and facilitation of long-term potentiation, independent of glutamergic signaling, were reported to be a few of the key mechanisms of AT4R's ability to improve cognitive ability (Wright and Harding, 2008).

\section{Conclusion and Future Perspectives}

At a molecular level, elevations in ROS and inflammatory cytokines are identified as an overarching paradigm for AT1Rmediated effects (Mehta and Griendling, 2007). Convincing evidence in the last decade has underscored the role of centrally expressed proinflammatory and pro-oxidant mediators in the progression of cardiovascular diseases and as hallmarks/risk factors for these diseases (Kishi et al., 2004; Wu et al., 2012; Haspula and Clark, 2018). By employing animal models, it was shown that elevations in central sympathetic outflow could be corrected by counteracting proinflammatory and pro-oxidant states (Shi et al., 2010a; Winklewski et al., 2015). The past decade has seen a significant increase in the number of studies highlighting the importance of the brain RAS in neurologic disorders such as dementia (Mogi et al., 2012) and MS (Lanz et al., 2010) and in neurodegenerative disorders such as Alzheimer and Parkinson diseases (Wright et al., 2013). Neuroinflammation and oxidative stress appear to be the common threads that connect the brain RAS to both cardiovascular and neurologic disorders (Zhang et al., 2010; Saavedra, 2012). AT1Rmediated elevation in ROS and multiple proinflammatory mediators are key factors in Ang II driving the progression of several pathologic conditions. Similar to many GPCRs, AT1Rs are known to crosstalk with other receptors, including those involved in mediating neuroprotection such as the Mas receptor (Von Bohlen und Halbach et al., 2000), AT2R (Inuzuka et al., 2016), and cannabinoid type-1 receptor (Rozenfeld et al., 2011; Szekeres et al., 2012; Haspula and Clark, 2016, 2017b). Hence, the pathologic significance of AT1R crosstalk with other receptors and systems present in different regions of the brain needs to be further explored. However, evidence of brain AT1R-mediated changes in receptors and systems that play a crucial role in neuroprotection has not been extensively 
researched. Understanding AT1R-mediated interactions with GPCRs that are known to be both functionally similar, as well as those that are deemed to be functionally antagonistic to AT1Rs, could aid in identifying the important players in Ang II-mediated neuroinflammation and oxidative stress, leading to the identification of therapeutic strategies that could be given in combination with central RAS antagonists. In addition, ARBs that are known to exhibit neuroprotective properties, independent of AT1R blockade, could well have potential for the treatment of neurologic disorders that are characterized by excessive inflammation. ARBs such as telmisartan are known to have pleiotropic effects apart from negating AT1R-induced oxidative stress and inflammation in the brain. Telmisartan has already been identified to have neuroprotective roles in preclinical studies conducted in mouse models of Alzheimer disease and stroke (ThoeneReineke et al., 2011; Saavedra, 2012; Torika et al., 2017). However, clinical studies have confirmed a lack of effectiveness of telmisartan in conferring neuroprotection in subacute stroke (Sare et al., 2013). Since neuroprotection has been demonstrated for ARBs such as candesartan and telmisartan, it could be worthwhile to investigate these drugs not only for cardiovascular disorders but also for neurologic outcomes (Benicky et al., 2009; Noda et al., 2012; Villapol and Saavedra, 2015). Whether ARBs such as telmisartan that target neuroinflammation through multiple modes of mechanisms have beneficial roles in neurologic disorders such as Alzheimer and Parkinson diseases remains to be seen.

\section{Authorship Contributions}

Wrote or contributed to the writing of the manuscript: Haspula, Clark.

\section{References}

Abdulla MH and Johns EJ (2017) The role of brain angiotensin II (type 2) receptors and nitric oxide in the renal sympathoinhibitory response to acute volume expansion in conscious rats. J Hypertens 35:338-347.

Adams HR, Szilagyi PG, Gebhardt L, and Lande MB (2010) Learning and attention problems among children with pediatric primary hypertension. Pediatrics 126 e1425-e1429.

Adriani W, Caprioli A, Granstrem O, Carli M, and Laviola G (2003) The spontaneously hypertensive-rat as an animal model of ADHD: evidence for impulsive and non-impulsive subpopulations. Neurosci Biobehav Rev 27:639-651.

Agarwal D, Dange RB, Raizada MK, and Francis J (2013) Angiotensin II causes imbalance between pro- and anti-inflammatory cytokines by modulating GSK-3 $\beta$ in neuronal culture. $\mathrm{Br} J$ Pharmacol 169:860-874.

Agarwal D, Welsch MA, Keller JN, and Francis J (2011) Chronic exercise modulates RAS components and improves balance between pro- and anti-inflammatory cytokines in the brain of SHR. Basic Res Cardiol 106:1069-1085.

Alanazi AZ, Patel P, and Clark MA (2014) p38 Mitogen-activated protein kinase is stimulated by both angiotensin II and angiotensin III in cultured rat astrocytes. $J$ Recept Signal Transduct Res 34:205-211.

Allen AM (2002) Inhibition of the hypothalamic paraventricular nucleus in spontaneously hypertensive rats dramatically reduces sympathetic vasomotor tone. $H y$ pertension 39:275-280.

Allen AM, Dosanjh JK, Erac M, Dassanayake S, Hannan RD, and Thomas WG (2006) Expression of constitutively active angiotensin receptors in the rostral ventrolateral medulla increases blood pressure. Hypertension 47:1054-1061.

Anderson EA, Sinkey CA, Lawton WJ, and Mark AL (1989) Elevated sympathetic nerve activity in borderline hypertensive humans. Evidence from direct intraneural recordings. Hypertension 14:177-183.

Aranda JM, Jr and Conti CR (2003) Angiotensin II blockade: a therapeutic strategy with wide applications. Clin Cardiol 26:500-502.

Atlas SA (2007) The renin-angiotensin aldosterone system: pathophysiological role and pharmacologic inhibition. J Manag Care Pharm 13 (Suppl B):9-20.

Bali A and Jaggi AS (2016) Angiotensin II-triggered kinase signaling cascade in the central nervous system. Rev Neurosci 27:301-315.

Barki-Harrington L, Luttrell LM, and Rockman HA (2003) Dual inhibition of betaadrenergic and angiotensin II receptors by a single antagonist: a functional role for receptor-receptor interaction in vivo. Circulation 108:1611-1618.

Barnes JM, Barnes NM, Costall B, Horovitz ZP, and Naylor RJ (1989) Angiotensin II inhibits the release of $[3 \mathrm{H}]$ acetylcholine from rat entorhinal cortex in vitro. Brain Res 491:136-143.

Benicky J, Sánchez-Lemus E, Pavel J, and Saavedra JM (2009) Anti-inflammatory effects of angiotensin receptor blockers in the brain and the periphery. Cell Mol Neurobiol 29:781-792.
Bennion DM, Haltigan E, Regenhardt RW, Steckelings UM, and Sumners C (2015) Neuroprotective mechanisms of the ACE2-angiotensin-(1-7)-Mas axis in stroke. Curr Hypertens Rep 17:3.

Bennion DM, Isenberg JD, Harmel AT, DeMars K, Dang AN, Jones CH, Pignataro ME, Graham JT, Steckelings UM, Alexander JC, et al. (2017) Post-stroke angiotensin II type 2 receptor activation provides long-term neuroprotection in aged rats. PLoS One 12:e180738.

Biancardi VC and Stern JE (2016) Compromised blood-brain barrier permeability: novel mechanism by which circulating angiotensin II signals to sympathoexcitatory centres during hypertension. J Physiol 594:1591-1600.

Biancardi VC, Stranahan AM, Krause EG, de Kloet AD, and Stern JE (2016) Cross talk between AT1 receptors and Toll-like receptor 4 in microglia contributes to angiotensin II-derived ROS production in the hypothalamic paraventricular nucleus. Am J Physiol Heart Circ Physiol 310:H404-H415.

Bickerton RK and Buckley JP (1961) Evidence for a central mechanism in angiotensin induced hypertension. Exp Biol Med 106:834-836.

Bodiga VL and Bodiga S (2013) Renin angiotensin system in cognitive function and dementia. Asian J Neurosci 2013:102602.

Booz GW, Conrad KM, Hess AL, Singer HA, and Baker KM (1992) Angiotensin-IIbinding sites on hepatocyte nuclei. Endocrinology 130:3641-3649.

Bosnyak S, Welungoda IK, Hallberg A, Alterman M, Widdop RE, and Jones ES (2010) Stimulation of angiotensin AT2 receptors by the non-peptide agonist, compound 21, evokes vasodepressor effects in conscious spontaneously hypertensive rats. Br J Pharmacol 159:709-716.

Braga VA, Soriano RN, Braccialli AL, de Paula PM, Bonagamba LGH, Paton JFR, and Machado BH (2007) Involvement of L-glutamate and ATP in the neurotransmission of the sympathoexcitatory component of the chemoreflex in the commissural nucleus tractus solitarii of awake rats and in the working heart-brainstem preparation. J Physiol 581:1129-1145.

Brooks VL and Malvin RL (1979) An intracerebral, physiological role for angiotensin: effects of central blockade. Fed Proc 38:2272-2275.

Burnier M and Zanchi A (2006) Blockade of the renin-angiotensin-aldosterone system: a key therapeutic strategy to reduce renal and cardiovascular events in patients with diabetes. $J$ Hypertens 24:11-25.

Campagnole-Santos MJ, Diz DI, and Ferrario CM (1988) Baroreceptor reflex modulation by angiotensin II at the nucleus tractus solitarii. Hypertension 11:I167-I171. Campbell DJ, Bouhnik J, Ménard J, and Corvol P (1984) Identity of angiotensinogen precursors of rat brain and liver. Nature 308:206-208.

Campos LA, Bader M, and Baltatu OC (2012) Brain renin-angiotensin system in hypertension, cardiac hypertrophy, and heart failure. Front Physiol 2:115.

Carey RM, Howell NL, Jin XH, and Siragy HM (2001) Angiotensin type 2 receptormediated hypotension in angiotensin type-1 receptor-blocked rats. Hypertension 38:1272-1277.

Case AJ, Tian J, and Zimmerman MC (2017) Increased mitochondrial superoxide in the brain, but not periphery, sensitizes mice to angiotensin II-mediated hypertension. Redox Biol 11:82-90.

Casto R and Phillips MI (1985) Neuropeptide action in nucleus tractus solitarius: angiotensin specificity and hypertensive rats. Am J Physiol 249:R341-R347.

Cato MJ and Toney GM (2005) Angiotensin II excites paraventricular nucleus neurons that innervate the rostral ventrolateral medulla: an in vitro patch-clamp study in brain slices. J Neurophysiol 93:403-413.

Chan JYH, Wang L-L, Chao Y-M, and Chan SHH (2003) Downregulation of basal iNOS at the rostral ventrolateral medulla is innate in SHR. Hypertension 41:563-570.

Chan SHH and Chan JYH (2012) Brain stem oxidative stress and its associated signaling in the regulation of sympathetic vasomotor tone. J Appl Physiol (1985) 113:1921-1928.

Cheng W-H, Lu P-J, Ho W-Y, Tung C-S, Cheng P-W, Hsiao M, and Tseng C-J (2010) Angiotensin II inhibits neuronal nitric oxide synthase activation through the ERK1/2-RSK signaling pathway to modulate central control of blood pressure. Circ Res 106:788-795.

Clark MA and Gonzalez N (2007) Angiotensin II stimulates rat astrocyte mitogenactivated protein kinase activity and growth through EGF and PDGF receptor transactivation. Regul Pept 144:115-122.

Clark MA, Nguyen C, and Tran H (2013) Distinct molecular effects of angiotensin II and angiotensin III in rat astrocytes. Int $J$ Hypertens 2013:782861.

Coble JP, Grobe JL, Johnson AK, and Sigmund CD (2015) Mechanisms of brain renin angiotensin system-induced drinking and blood pressure: importance of the subfornical organ. Am J Physiol Regul Integr Comp Physiol 308:R238-R249.

Coble JP, Johnson RF, Cassell MD, Johnson AK, Grobe JL, and Sigmund CD (2014) Activity of protein kinase C- $\alpha$ within the subfornical organ is necessary for fluid intake in response to brain angiotensin. Hypertension 64:141-148.

Côté F, Do TH, Laflamme L, Gallo JM, and Gallo-Payet N (1999) Activation of the AT (2) receptor of angiotensin II induces neurite outgrowth and cell migration in microexplant cultures of the cerebellum. J Biol Chem 274:31686-31692.

Danyel LA, Schmerler P, Paulis L, Unger T, and Steckelings UM (2013) Impact of AT2-receptor stimulation on vascular biology, kidney function, and blood pressure. Integr Blood Press Control 6:153-161.

Davies NM, Kehoe PG, Ben-Shlomo Y, and Martin RM (2011) Associations of antihypertensive treatments with Alzheimer's disease, vascular dementia, and other dementias. J Alzheimers Dis 26:699-708.

de Gasparo M, Catt KJ, Inagami T, Wright JW, and Unger T (2000) International Union of Pharmacology. XXIII. The angiotensin II receptors. Pharmacol Rev 52: $415-472$.

de Kloet AD, Steckelings UM, and Sumners C (2017) Protective angiotensin type 2 receptors in the brain and hypertension. Curr Hypertens Rep 19:46.

De Mello WC (2008) Intracellular and extracellular renin have opposite effects on the regulation of heart cell volume. Implications for myocardial ischaemia. J Renin Angiotensin Aldosterone Syst 9:112-118.

de Oliveira-Sales EB, Nishi EE, Boim MA, Dolnikoff MS, Bergamaschi CT, and Campos RR (2010) Upregulation of AT1R and iNOS in the rostral 
ventrolateral medulla (RVLM) is essential for the sympathetic hyperactivity and hypertension in the 2K-1C Wistar rat model. Am J Hypertens 23:708-715.

Deschepper CF, Bouhnik J, and Ganong WF (1986) Colocalization of angiotensinogen and glial fibrillary acidic protein in astrocytes in rat brain. Brain Res 374:195-198. Edwards MA, Loxley RA, Powers-Martin K, Lipski J, McKitrick DJ, Arnolda LF, and Phillips JK (2004) Unique levels of expression of N-methyl-D-aspartate receptor subunits and neuronal nitric oxide synthase in the rostral ventrolateral medulla of the spontaneously hypertensive rat. Brain Res Mol Brain Res 129:33-43.

Farag E, Sessler DI, Ebrahim Z, Kurz A, Morgan J, Ahuja S, Maheshwari K, and John Doyle D (2017) The renin angiotensin system and the brain: new developments. J Clin Neurosci 46:1-8.

Faulk K, Shell B, Nedungadi TP, and Cunningham JT (2017) Role of angiotensinconverting enzyme 1 within the median preoptic nucleus following chronic intermittent hypoxia. Am J Physiol Regul Integr Comp Physiol 312:R245-R252.

Fazal K, Perera G, Khondoker M, Howard R, and Stewart R (2017) Associations of centrally acting ACE inhibitors with cognitive decline and survival in Alzheimer's disease. BJPsych Open 3:158-164.

Ferrario CM, Brosnihan KB, Diz DI, Jaiswal N, Khosla MC, Milsted A, and Tallant EA (1991) Angiotensin-(1-7): a new hormone of the angiotensin system. Hypertension 18:III126-III133.

Fields RD and Burnstock G (2006) Purinergic signalling in neuron-glia interactions. Nat Rev Neurosci 7:423-436.

Fisher JP and Paton JFR (2012) The sympathetic nervous system and blood pressure in humans: implications for hypertension. J Hum Hypertens 26:463-475.

Fisher JP, Young CN, and Fadel PJ (2009) Central sympathetic overactivity: maladies and mechanisms. Auton Neurosci 148:5-15.

Fyhrquist F, Metsärinne K, and Tikkanen I (1995) Role of angiotensin II in blood pressure regulation and in the pathophysiology of cardiovascular disorders. J Hum Hypertens 9 (Suppl 5):S19-S24.

Ganong WF (1994) Origin of the angiotensin II secreted by cells. Proc Soc Exp Biol Med 205:213-239.

Ganten D, Hermann K, Bayer C, Unger T, and Lang RE (1983) Angiotensin synthesis in the brain and increased turnover in hypertensive rats. Science 221:869-871.

Gao L and Zucker IH (2011) AT2 receptor signaling and sympathetic regulation. Curr Opin Pharmacol 11:124-130.

Gao Q, Ou Z, Jiang T, Tian Y-Y, Zhou J-S, Wu L, Shi J-Q, and Zhang Y-D (2017) Azilsartan ameliorates apoptosis of dopaminergic neurons and rescues characteristic parkinsonian behaviors in a rat model of Parkinson's disease. Oncotarget 8: 24099-24109.

Gao Y, O'Caoimh R, Healy L, Kerins DM, Eustace J, Guyatt G, Sammon D, and Molloy DW (2013) Effects of centrally acting ACE inhibitors on the rate of cognitive decline in dementia. BMJ Open 3:e002881.

Gelband CH, Sumners C, Lu D, and Raizada MK (1998) Angiotensin receptors and norepinephrine neuromodulation: implications of functional coupling. Regul Pept 73:141-147.

Gendron L, Payet MD, and Gallo-Payet N (2003) The angiotensin type 2 receptor of angiotensin II and neuronal differentiation: from observations to mechanisms. $J$ Mol Endocrinol 31:359-372.

Gourine AV, Wood JD, and Burnstock G (2009) Purinergic signalling in autonomic control. Trends Neurosci 32:241-248.

Gowrisankar YV and Clark MA (2016a) Angiotensin II induces interleukin-6 expression in astrocytes: role of reactive oxygen species and NF-кB. Mol Cell Endocrinol 437:130-141.

Gowrisankar YV and Clark MA (2016b) Angiotensin II regulation of angiotensinconverting enzymes in spontaneously hypertensive rat primary astrocyte cultures. $J$ Neurochem 138:74-85.

Gowrisankar YV and Clark MA (2016c) Regulation of angiotensinogen expression by angiotensin II in spontaneously hypertensive rat primary astrocyte cultures. Brain Res 1643:51-58.

Grassi G, Seravalle G, and Quarti-Trevano F (2010) The 'neuroadrenergic hypothesis' in hypertension: current evidence. Exp Physiol 95:581-586.

Gutkind JS, Kurihara M, Castren E, and Saavedra JM (1988) Increased concentration of angiotensin II binding sites in selected brain areas of spontaneously hypertensive rats. $J$ Hypertens 6:79-84.

Haack KKV, Mitra AK, and Zucker IH (2013) NF-kB and CREB are required for angiotensin II type 1 receptor upregulation in neurons. PLoS One 8:e78695.

Hajjar I, Brown L, Mack WJ, and Chui H (2012) Impact of angiotensin receptor blockers on Alzheimer disease neuropathology in a large brain autopsy series. Arch Neurol 69:1632-1638.

Hall JE (1986) Control of sodium excretion by angiotensin II: intrarenal mechanisms and blood pressure regulation. Am J Physiol 250:R960-R972.

Hamilton TA, Handa RK, Harding JW, and Wright JW (2001) A role for the angiotensin IV/AT4 system in mediating natriuresis in the rat. Peptides 22:935-944.

Haspula D and Clark M (2017a) Regulation of neuroinflammatory cytokines by angiotensin and cannabinoid systems in SHR astrocytes. FASEB $J$ 31:lb554-lb554.

Haspula D and Clark MA (2016) Heterologous regulation of the cannabinoid type 1 receptor by angiotensin II in astrocytes of spontaneously hypertensive rats. $J$ Neurochem 139:523-536.

Haspula D and Clark MA (2017b) MAPK activation patterns of AT1R and CB1R in SHR versus Wistar astrocytes: evidence of CB1R hypofunction and crosstalk between AT1R and CB1R. Cell Signal 40:81-90.

Haspula D and Clark MA (2018) Neuroinflammation and sympathetic overactivity: mechanisms and implications in hypertension. Auton Neurosci 210:10-17.

Hendricks AS, Shaltout HA, Chappell MC, and Diz DI (2017) Central angiotensin-(17) treatment attenuates ERK $1 / 2$ expression and oxidative stress in the dorsal medulla of betamethasone-exposed sheep that associates with improved blood pressure and baroreflex sensitivity (Abstract). Hypertension 70 (Suppl 1):A145.

Hermann K, McDonald W, Unger T, Lang RE, and Ganten D (1984) Angiotensin biosynthesis and concentrations in brain of normotensive and hypertensive rats. $J$ Physiol (Paris) 79:471-480.
Higashino H, Niwa A, Satou T, Ohta Y, Hashimoto S, Tabuchi M, and Ooshima K (2009) Immunohistochemical analysis of brain lesions using S100B and glial fibrillary acidic protein antibodies in arundic acid- (ONO-2506) treated strokeprone spontaneously hypertensive rats. J Neural Transm (Vienna) 116:1209-1219. Hirooka Y, Shigematsu H, Kishi T, Kimura Y, Ueta Y, and Takeshita A (2003) Reduced nitric oxide synthase in the brainstem contributes to enhanced sympathetic drive in rats with heart failure. $J$ Cardiovasc Pharmacol 42 (Suppl 1):S111-S115. Ho JK and Nation DA; Alzheimer's Disease Neuroimaging Initiative (2017) Memory is preserved in older adults taking AT1 receptor blockers. Alzheimers Res Ther $\mathbf{9}$ : 33.

Hoffmann BR, Stodola TJ, Wagner JR, Didier DN, Exner EC, Lombard JH, and Greene AS (2017) Mechanisms of Mas1 receptor-mediated signaling in the vascular endothelium. Arterioscler Thromb Vasc Biol 37:433-445.

Hu L, Zhu D-N, Yu Z, Wang JQ, Sun Z-J, and Yao T (2002) Expression of angiotensin II type 1 (AT(1)) receptor in the rostral ventrolateral medulla in rats. $J A p p l$ Physiol (1985) 92:2153-2161.

Huang BS and Leenen FHH (2009) The brain renin-angiotensin-aldosterone system: a major mechanism for sympathetic hyperactivity and left ventricular remodeling and dysfunction after myocardial infarction. Curr Heart Fail Rep 6:81-88.

Huang X-C, Deng T, and Sumners C (1998) Angiotensin II stimulates activation of Fos-regulating kinase and c-Jun $\mathrm{NH}_{2}$-terminal kinase in neuronal cultures from rat brain. Endocrinology 139:245-251.

Inuzuka T, Fujioka Y, Tsuda M, Fujioka M, Satoh AO, Horiuchi K, Nishide S, Nanbo A, Tanaka S, and Ohba Y (2016) Attenuation of ligand-induced activation of angiotensin II type 1 receptor signaling by the type 2 receptor via protein kinase C. Sci Rep 6:21613.

Isegawa K, Hirooka Y, Katsuki M, Kishi T, and Sunagawa K (2014) Angiotensin II type 1 receptor expression in astrocytes is upregulated leading to increased mortality in mice with myocardial infarction-induced heart failure. Am J Physiol Heart Circ Physiol 307:H1448-H1455.

Ito S, Komatsu K, Tsukamoto K, Kanmatsuse K, and Sved AF (2002) Ventrolateral medulla AT1 receptors support blood pressure in hypertensive rats. Hypertension 40:552-559.

Ito S, Komatsu K, Tsukamoto K, and Sved AF (2000) Excitatory amino acids in the rostral ventrolateral medulla support blood pressure in spontaneously hypertensive rats. Hypertension 35:413-417.

John GR, Lee SC, and Brosnan CF (2003) Cytokines: powerful regulators of glial cell activation. Neuroscientist 9:10-22.

Joseph JP, Mecca AP, Regenhardt RW, Bennion DM, Rodríguez V, Desland F, Patel NA, Pioquinto DJ, Unger T, Katovich MJ, et al. (2014) The angiotensin type 2 receptor agonist Compound 21 elicits cerebroprotection in endothelin-1 induced ischemic stroke. Neuropharmacology 81:134-141.

Kandalam U and Clark MA (2010) Angiotensin II activates JAK2/STAT3 pathway and induces interleukin-6 production in cultured rat brainstem astrocytes. Regul Pept 159:110-116.

Kandalam U, Sarmiento N, Haspula D, and Clark MA (2015) Angiotensin III induces signal transducer and activator of transcription 3 and interleukin-6 mRNA levels in cultured rat astrocytes. J Renin Angiotensin Aldosterone Syst 16:758-767.

Kang Y-M, Ma Y, Zheng J-P, Elks C, Sriramula S, Yang Z-M, and Francis J (2009) Brain nuclear factor-kappa B activation contributes to neurohumoral excitation in angiotensin II-induced hypertension. Cardiovasc Res 82:503-512.

Kangussu LM, Guimaraes PS, Nadu AP, Melo MB, Santos RAS, and CampagnoleSantos MJ (2015) Activation of angiotensin-(1-7)/Mas axis in the brain lowers blood pressure and attenuates cardiac remodeling in hypertensive transgenic (mRen2)27 rats. Neuropharmacology 97:58-66.

Kehoe PG, Wong S, Al Mulhim N, Palmer LE, and Miners JS (2016) Angiotensinconverting enzyme 2 is reduced in Alzheimer's disease in association with increasing amyloid- $\beta$ and tau pathology. Alzheimers Res Ther 8:50.

Kimura Y, Hirooka Y, Kishi T, Ito K, Sagara Y, and Sunagawa K (2009) Role of inducible nitric oxide synthase in rostral ventrolateral medulla in blood pressure regulation in spontaneously hypertensive rats. Clin Exp Hypertens 31:281-286.

Kishi T, Hirooka Y, Ito K, Sakai K, Shimokawa H, and Takeshita A (2002) Cardiovascular effects of overexpression of endothelial nitric oxide synthase in the rostral ventrolateral medulla in stroke-prone spontaneously hypertensive rats. Hypertension 39:264-268.

Kishi T, Hirooka Y, Kimura Y, Ito K, Shimokawa H, and Takeshita A (2004) Increased reactive oxygen species in rostral ventrolateral medulla contribute to neural mechanisms of hypertension in stroke-prone spontaneously hypertensive rats. Circulation 109:2357-2362.

Kishi T, Hirooka Y, Konno S, Ogawa K, and Sunagawa K (2010) Angiotensin II type 1 receptor-activated caspase-3 through ras/mitogen-activated protein kinase/extracellular signal-regulated kinase in the rostral ventrolateral medulla is involved in sympathoexcitation in stroke-prone spontaneously hypertensive rats. Hypertension 55:291-297.

Kishi T, Hirooka Y, Sakai K, Shigematsu H, Shimokawa H, and Takeshita A (2001) Overexpression of eNOS in the RVLM causes hypotension and bradycardia via GABA release. Hypertension 38:896-901.

Koka V, Huang XR, Chung ACK, Wang W, Truong LD, and Lan HY (2008) Angiotensin II up-regulates angiotensin I-converting enzyme (ACE), but down-regulates ACE2 via the AT1-ERK/p38 MAP kinase pathway. Am J Pathol 172:1174-1183.

Kong J, Zhang K, Meng X, Zhang Y, and Zhang C (2015) Dose-dependent bidirectional effect of angiotensin IV on abdominal aortic aneurysm via variable angiotensin receptor stimulation. Hypertension 66:617-626.

Korner P, Bobik A, Oddie C, and Friberg P (1993) Sympathoadrenal system is critical for structural changes in genetic hypertension. Hypertension 22:243-252.

Kramár EA, Harding JW, and Wright JW (1997) Angiotensin II- and IV-induced changes in cerebral blood flow. Roles of AT1, AT2, and AT4 receptor subtypes. Regul Pept 68:131-138.

Kumagai H, Oshima N, Matsuura T, Iigaya K, Imai M, Onimaru H, Sakata K, Osaka M, Onami T, Takimoto C, et al. (2012) Importance of rostral ventrolateral medulla 
neurons in determining efferent sympathetic nerve activity and blood pressure. Hypertens Res 35:132-141.

Labandeira-Garcia JL, Rodríguez-Perez AI, Garrido-Gil P, Rodriguez-Pallares J, Lanciego JL, and Guerra MJ (2017) Brain renin-angiotensin system and microglial polarization: implications for aging and neurodegeneration. Front Aging Neurosci 9:129.

Lanz TV, Ding Z, Ho PP, Luo J, Agrawal AN, Srinagesh H, Axtell R, Zhang H, Platten M, Wyss-Coray T, et al. (2010) Angiotensin II sustains brain inflammation in mice via TGF- $\beta$. J Clin Invest 120:2782-2794.

Laudisio A, Lo Monaco MR, Silveri MC, Bentivoglio AR, Vetrano DL, Pisciotta MS, Brandi V, Bernabei R, and Zuccalà G (2017) Use of ACE-inhibitors and falls in patients with Parkinson's disease. Gait Posture 54:39-44.

Lavoie JL, Liu X, Bianco RA, Beltz TG, Johnson AK, and Sigmund CD (2006) Evidence supporting a functional role for intracellular renin in the brain. Hypertension 47:461-466.

Lavoie JL and Sigmund CD (2003) Minireview: overview of the renin-angiotensin system-an endocrine and paracrine system. Endocrinology 144:2179-2183.

Lee HM, Lee C-K, Lee SH, Roh HY, Bae YM, Lee K-Y, Lim J, Park P-J, Park T-K, Lee $\mathrm{YL}$, et al. (2007) p38 mitogen-activated protein kinase contributes to angiotensin II-stimulated migration of rat aortic smooth muscle cells. J Pharmacol Sci 105:74-81.

Lee J, Albiston AL, Allen AM, Mendelsohn FA, Ping SE, Barrett GL, Murphy M, Morris MJ, McDowall SG, and Chai SY (2004) Effect of I.C.V. injection of AT4 receptor ligands, NLE1-angiotensin IV and LVV-hemorphin 7, on spatial learning in rats. Neuroscience 124:341-349.

Lee Y-C, Lin C-H, Wu R-M, Lin J-W, Chang C-H, and Lai M-S (2014) Antihypertensive agents and risk of Parkinson's disease: a nationwide cohort study. PLoS One 9:e98961.

Lee-Kirsch MA, Gaudet F, Cardoso MC, and Lindpaintner K (1999) Distinct renin isoforms generated by tissue-specific transcription initiation and alternative splicing. Circ Res 84:240-246.

Lenkei Z, Corvol P, and Llorens-Cortes C (1995) The angiotensin receptor subtype AT1A predominates in rat forebrain areas involved in blood pressure, body fluid homeostasis and neuroendocrine control. Brain Res Mol Brain Res 30:53-60.

Leonhardt J, Villela DC, Teichmann A, Münter L-M, Mayer MC, Mardahl M, Kirsch S, Namsolleck P, Lucht K, Benz V, et al. (2017) Evidence for heterodimerization and functional interaction of the angiotensin Type 2 receptor and the receptor MAS. Hypertension 69:1128-1135.

Li D-P and Pan H-L (2005) Angiotensin II attenuates synaptic GABA release and excites paraventricular-rostral ventrolateral medulla output neurons. J Pharmacol Exp Ther 313:1035-1045

Li N-C, Lee A, Whitmer RA, Kivipelto M, Lawler E, Kazis LE, and Wolozin B (2010) Use of angiotensin receptor blockers and risk of dementia in a predominantly male population: prospective cohort analysis. BMJ 340:b5465.

Li Y, Li X-H, and Yuan H (2012) Angiotensin II type-2 receptor-specific effects on the cardiovascular system. Cardiovasc Diagn Ther 2:56-62.

Liu G, Hosomi N, Hitomi H, Pelisch N, Fu H, Masugata H, Murao K, Ueno M, Matsumoto M, and Nishiyama A (2011a) Angiotensin II induces human astrocyte senescence through reactive oxygen species production. Hypertens Res 34:479-483.

Liu M, Shi P, and Sumners C (2016) Direct anti-inflammatory effects of angiotensin(1-7) on microglia. J Neurochem 136:163-171.

Liu W, Tang Y, and Feng J (2011b) Cross talk between activation of microglia and astrocytes in pathological conditions in the central nervous system. Life Sci $\mathbf{8 9}$ 141-146.

Long DA, Price KL, Herrera-Acosta J, and Johnson RJ (2004) How does angiotensin II cause renal injury? Hypertension 43:722-723.

Marina N, Ang R, Machhada A, Kasymov V, Karagiannis A, Hosford PS, Mosienko V, Teschemacher AG, Vihko P, Paton JFR, et al. (2015) Brainstem hypoxia contributes to the development of hypertension in the spontaneously hypertensive rat. Hypertension 65:775-783.

Marina N, Tang F, Figueiredo M, Mastitskaya S, Kasimov V, Mohamed-Ali V, Rolof E, Teschemacher AG, Gourine AV, and Kasparov S (2013) Purinergic signalling in the rostral ventro-lateral medulla controls sympathetic drive and contributes to the progression of heart failure following myocardial infarction in rats. Basic Res Cardiol 108:317.

Marina N, Teschemacher AG, Kasparov S, and Gourine AV (2016) Glia, sympathetic activity and cardiovascular disease. Exp Physiol 101:565-576.

Mascolo A, Sessa M, Scavone C, De Angelis A, Vitale C, Berrino L, Rossi F, Rosano G, and Capuano A (2017) New and old roles of the peripheral and brain renin angiotensin-aldosterone system (RAAS): focus on cardiovascular and neurological diseases. Int $J$ Cardiol 227:734-742.

Matavelli LC and Siragy HM (2015) AT2 receptor activities and pathophysiological implications. J Cardiovasc Pharmacol 65:226-232.

Matsuda T, Shibata K, Abe M, Tomonaga M, and Furukawa T (1987) Potentiation of pressor response to angiotensin II at the preoptic area in spontaneously hypertensive rat. Life Sci 41:749-754.

Matsumura K, Averill DB, and Ferrario CM (1998) Angiotensin II acts at AT1 receptors in the nucleus of the solitary tract to attenuate the baroreceptor reflex. $\mathrm{Am}$ J Physiol 275:R1611-R1619.

Matsushita T, Isobe N, Kawajiri M, Mogi M, Tsukuda K, Horiuchi M, Ohyagi Y, and Kira J (2010) CSF angiotensin II and angiotensin-converting enzyme levels in anti-aquaporin-4 autoimmunity. J Neurol Sci 295:41-45.

Matsuura T, Kumagai H, Kawai A, Onimaru H, Imai M, Oshima N, Sakata K, and Saruta T (2002) Rostral ventrolateral medulla neurons of neonatal WistarKyoto and spontaneously hypertensive rats. Hypertension 40:560-565.

McKinney CA, Fattah C, Loughrey CM, Milligan G, and Nicklin SA (2014) Angiotensin-(1-7) and angiotensin-(1-9): function in cardiac and vascular remodelling. Clin Sci (Lond) 126:815-827.

Mehta PK and Griendling KK (2007) Angiotensin II cell signaling: physiological and pathological effects in the cardiovascular system. Am J Physiol Cell Physiol 292: C82-C97.
Mendelsohn FA, Jenkins TA, and Berkovic SF (1993) Effects of angiotensin II on dopamine and serotonin turnover in the striatum of conscious rats. Brain Res $\mathbf{6 1 3}$ $221-229$

Mertens B, Vanderheyden P, Michotte Y, and Sarre S (2010) Direct angiotensin II type 2 receptor stimulation decreases dopamine synthesis in the rat striatum. Neuropharmacology 58:1038-1044.

Min L-J, Mogi M, Iwanami J, Sakata A, Jing F, Tsukuda K, Ohshima K, and Horiuchi M (2011) Angiotensin II and aldosterone-induced neuronal damage in neurons through an astrocyte-dependent mechanism. Hypertens Res 34:773-778.

Min L-J, Mogi M, Tsukuda K, Jing F, Ohshima K, Nakaoka H, Kan-No H, Wang X-L, Chisaka T, Bai H-Y, et al. (2014) Direct stimulation of angiotensin II type 2 receptor initiated after stroke ameliorates ischemic brain damage. Am J Hypertens 27:1036-1044.

Modgil A, Zhang Q, Pingili A, Singh N, Yao F, Ge J, Guo L, Xuan C, O’Rourke ST, and Sun C (2012) Angiotensin-(1-7) attenuates the chronotropic response to angiotensin II via stimulation of PTEN in the spontaneously hypertensive rat neurons. Am J Physiol Heart Circ Physiol 302:H1116-H1122.

Mogi M and Horiuchi M (2009) Effects of angiotensin II receptor blockers on dementia. Hypertens Res 32:738-740.

Mogi M, Iwanami J, and Horiuchi M (2012) Roles of brain angiotensin II in cognitive function and dementia. Int $J$ Hypertens 2012:169649.

Montani J-P and Van Vliet BN (2004) General physiology and pathophysiology of the renin-angiotensin system, in Angiotensin (Unger T and Schölkens BA eds) vol 1, pp $3-29$, Springer, Berlin.

Montezano AC, Nguyen Dinh Cat A, Rios FJ, and Touyz RM (2014) Angiotensin II and vascular injury. Curr Hypertens Rep 16:431.

Mori J, Patel VB, Abo Alrob O, Basu R, Altamimi T, Desaulniers J, Wagg CS, Kassiri Z, Lopaschuk GD, and Oudit GY (2014a) Angiotensin 1-7 ameliorates diabetic cardiomyopathy and diastolic dysfunction in $\mathrm{db} / \mathrm{db}$ mice by reducing lipotoxicity and inflammation. Circ Heart Fail 7:327-339.

Mori J, Patel VB, Ramprasath T, Alrob OA, DesAulniers J, Scholey JW, Lopaschuk GD, and Oudit GY (2014b) Angiotensin 1-7 mediates renoprotection against diabetic nephropathy by reducing oxidative stress, inflammation, and lipotoxicity. Am J Physiol Renal Physiol 306:F812-F821.

Morimoto S, Cassell MD, and Sigmund CD (2002) Glia- and neuron-specific expression of the renin-angiotensin system in brain alters blood pressure, water intake, and salt preference. J Biol Chem 277:33235-33241.

Morris MC, Scherr PA, Hebert LE, Bennett DA, Wilson RS, Glynn RJ, and Evans DA (2000) The cross-sectional association between blood pressure and Alzheimer's disease in a biracial community population of older persons. J Gerontol A Biol Sci Med Sci 55:M130-M136.

Morris MJ, Wilson WL, Starbuck EM, and Fitts DA (2002) Forebrain circumventricular organs mediate salt appetite induced by intravenous angiotensin II in rats. Brain Res 949:42-50

Mosqueda-Garcia R, Tseng CJ, Appalsamy M, and Robertson D (1990) Cardiovascular effects of microinjection of angiotensin II in the brainstem of renal hypertensive rats. $J$ Pharmacol Exp Ther 255:374-381.

Muela HC, Costa-Hong VA, Yassuda MS, Moraes NC, Memória CM, Machado MF, Macedo TA, Shu EBS, Massaro AR, Nitrini R, et al. (2017) Hypertension severity is associated with impaired cognitive performance. J Am Heart Assoc 6:e004579.

Muratani H, Averill DB, and Ferrario CM (1991) Effect of angiotensin II in ventrolateral medulla of spontaneously hypertensive rats. Am J Physiol 260:R977-R984. Namsolleck P, Recarti C, Foulquier S, Steckelings UM, and Unger T (2014) AT(2) receptor and tissue injury: therapeutic implications. Curr Hypertens Rep 16:416.

Nautiyal M, Arnold AC, Chappell MC, and Diz DI (2013) The brain renin-angiotensin system and mitochondrial function: influence on blood pressure and baroreflex in transgenic rat strains. Int $J$ Hypertens 2013:136028.

Negussie S, Lymperopoulos A, and Clark MA (2017) Differential ßarrestin1-mediated signaling in spontaneously hypertensive versus normotensive rat-derived astrocytes (Abstract). FASEB $J$ 31 (Suppl):827.3.

Negussie S, Lymperopoulos A, and Clark MA (2016) Unexpected negative role of the AT1R adaptor protein $\beta$ arrestin 1 in the ERK1/2 activation of SHR-derived primary astrocytes (Abstract). FASEB $J \mathbf{3 0}$ (Suppl):719.6

Nelson L, Gard P, and Tabet N (2014) Hypertension and inflammation in Alzheimer's disease: close partners in disease development and progression! $J$ Alzheimers Dis 41:331-343.

Noda A, Fushiki H, Murakami Y, Sasaki H, Miyoshi S, Kakuta H, and Nishimura S (2012) Brain penetration of telmisartan, a unique centrally acting angiotensin II type 1 receptor blocker, studied by PET in conscious rhesus macaques. $\mathrm{Nucl} \mathrm{Med}$ Biol 39:1232-1235.

Nozoe M, Hirooka Y, Koga Y, Araki S, Konno S, Kishi T, Ide T, and Sunagawa K (2008) Mitochondria-derived reactive oxygen species mediate sympathoexcitation induced by angiotensin II in the rostral ventrolateral medulla. J Hypertens 26 $2176-2184$

Oliveira-Sales EB, Nishi EE, Carillo BA, Boim MA, Dolnikoff MS, Bergamaschi CT, and Campos RR (2009) Oxidative stress in the sympathetic premotor neurons contributes to sympathetic activation in renovascular hypertension. Am J Hyper tens 22:484-492.

Ongali B, Nicolakakis N, Tong X-K, Aboulkassim T, Papadopoulos P, Rosa-Neto P, Lecrux C, Imboden H, and Hamel E (2014) Angiotensin II type 1 receptor blocker losartan prevents and rescues cerebrovascular, neuropathological and cognitive deficits in an Alzheimer's disease model. Neurobiol Dis 68:126-136.

Patel VB, Bodiga S, Fan D, Das SK, Wang Z, Wang W, Basu R, Zhong J, Kassiri Z, and Oudit GY (2012) Cardioprotective effects mediated by angiotensin II type 1 receptor blockade and enhancing angiotensin 1-7 in experimental heart failure in angiotensin-converting enzyme 2-null mice. Hypertension 59:1195-1203.

Paton JF, Deuchars J, Ahmad Z, Wong LF, Murphy D, and Kasparov S (2001) Adenoviral vector demonstrates that angiotensin II-induced depression of the cardiac baroreflex is mediated by endothelial nitric oxide synthase in the nucleus tractus solitarii of the rat. $J$ Physiol 531:445-458. 
Paton JF and Kasparov S (1999) Differential effects of angiotensin II on cardiorespiratory reflexes mediated by nucleus tractus solitarii - a microinjection study in the rat. $J$ Physiol 521:213-225.

Paton JFR and Waki H (2009) Is neurogenic hypertension related to vascular inflammation of the brainstem? Neurosci Biobehav Rev 33:89-94.

Paul M, Poyan Mehr A, and Kreutz R (2006) Physiology of local renin-angiotensin systems. Physiol Rev 86:747-803.

Phillips MI (1983) New evidence for brain angiotensin and for its role in hypertension. Fed Proc 42:2667-2672.

Phillips MI, Shen L, Richards EM, and Raizada MK (1993) Immunohistochemical mapping of angiotensin AT1 receptors in the brain. Regul Pept 44:95-107.

Platten M, Youssef S, Hur EM, Ho PP, Han MH, Lanz TV, Phillips LK, Goldstein MJ, Bhat R, Raine CS, et al. (2009) Blocking angiotensin-converting enzyme induces potent regulatory T cells and modulates TH1- and TH17-mediated autoimmunity. Proc Natl Acad Sci USA 106:14948-14953.

Polson JW, Dampney RA, Boscan P, Pickering AE, and Paton JF (2007) Differential baroreflex control of sympathetic drive by angiotensin II in the nucleus tractus solitarii. Am J Physiol Regul Integr Comp Physiol 293:R1954-R1960.

Qadri F, Arens T, Schwarz E-C, Häuser W, Dendorfer A, and Dominiak P (2003) Brain nitric oxide synthase activity in spontaneously hypertensive rats during the development of hypertension. J Hypertens 21:1687-1694.

Qadri F, Badoer E, Stadler T, and Unger T (1991) Angiotensin II-induced noradrenaline release from anterior hypothalamus in conscious rats: a brain microdialysis study. Brain Res 563:137-141.

Qadri F, Culman J, Veltmar A, Maas K, Rascher W, and Unger T (1993) Angiotensin II-induced vasopressin release is mediated through alpha-1 adrenoceptors and angiotensin II AT1 receptors in the supraoptic nucleus. J Pharmacol Exp Ther 267:567-574.

Qiu C, von Strauss E, Fastbom J, Winblad B, and Fratiglioni L (2003) Low blood pressure and risk of dementia in the Kungsholmen project: a 6-year follow-up study. Arch Neurol 60:223-228.

Reitz C, Tang MX, Manly J, Mayeux R, and Luchsinger JA (2007) Hypertension and the risk of mild cognitive impairment. Arch Neurol 64:1734-1740.

Rettig R, Healy DP, and Printz MP (1986) Cardiovascular effects of microinjections of angiotensin II into the nucleus tractus solitarii. Brain Res 364:233-240.

Rodríguez V, de Kloet A, Llerena V, Kitchen-Pareja MC, and Sumners C (2015) Prorenin-induced pro-inflammatory effect in hypothalamic astrocytes from spontaneously hypertensive rats (Abstract). Hypertension 62 (Suppl 1):163

Rodriguez-Perez AI, Borrajo A, Diaz-Ruiz C, Garrido-Gil P, and Labandeira-Garcia JL (2016) Crosstalk between insulin-like growth factor-1 and angiotensin-II in dopaminergic neurons and glial cells: role in neuroinflammation and aging. Oncotarget 7:30049-30067.

Royea J, Zhang L, Tong X-K, and Hamel E (2017) Angiotensin IV receptors mediate the cognitive and cerebrovascular benefits of losartan in a mouse model of $\mathrm{Alz}$ heimer's disease. J Neurosci 37:5562-5573.

Rozenfeld R, Gupta A, Gagnidze K, Lim MP, Gomes I, Lee-Ramos D, Nieto N, and Devi LA (2011) AT1R-CB $\mathrm{C}_{1}$ heteromerization reveals a new mechanism for the pathogenic properties of angiotensin II. EMBO J 30:2350-2363.

Saavedra JM (2012) Angiotensin II AT( ${ }_{1}$ ) receptor blockers as treatments for in flammatory brain disorders. Clin Sci (Lond) 123:567-590

Sampaio WO, Henrique de Castro C, Santos RAS, Schiffrin EL, and Touyz RM (2007) Angiotensin-(1-7) counterregulates angiotensin II signaling in human endothelial cells. Hypertension 50:1093-1098.

Sare GM, Ghadami A, Ankolekar S, England T, Hammonds F, Adrian M, Clarke J, Stokes L, Auer D, and Bath PMW (2013) Effect of telmisartan on cerebral and systemic haemodynamics in patients with recent ischaemic stroke: a randomised controlled trial. ISRN Stroke 2013:1-9.

Saxby BK, Harrington F, Wesnes KA, McKeith IG, and Ford GA (2008) Candesartan and cognitive decline in older patients with hypertension: a substudy of the SCOPE trial. Neurology 70:1858-1866.

Seyedabadi M, Goodchild AK, and Pilowsky PM (2001) Differential role of kinases in brain stem of hypertensive and normotensive rats. Hypertension 38:1087-1092.

Shapiro MS, Wollmuth LP, and Hille B (1994) Angiotensin II inhibits calcium and M current channels in rat sympathetic neurons via G proteins. Neuron 12:1319-1329.

Shi P, Diez-Freire C, Jun JY, Qi Y, Katovich MJ, Li Q, Sriramula S, Francis J, Sumners C, and Raizada MK (2010a) Brain microglial cytokines in neurogenic hypertension. Hypertension 56:297-303.

Shi P, Grobe JL, Desland FA, Zhou G, Shen XZ, Shan Z, Liu M, Raizada MK, and Sumners C (2014) Direct pro-inflammatory effects of prorenin on microglia. PLoS One 9:e92937.

Shi P, Raizada MK, and Sumners C (2010b) Brain cytokines as neuromodulators in cardiovascular control. Clin Exp Pharmacol Physiol 37:e52-e57.

Shi Z, Gan X-B, Fan Z-D, Zhang F, Zhou Y-B, Gao X-Y, De W, and Zhu G-Q (2011) Inflammatory cytokines in paraventricular nucleus modulate sympathetic activity and cardiac sympathetic afferent reflex in rats. Acta Physiol (Oxf) 203:289-297.

Simpson JB, Epstein AN, and Camardo JS, Jr (1978) Localization of receptors for the dipsogenic action of angiotensin II in the subfornical organ of rat. J Comp Physiol Psychol 92:581-601.

Skoog I, Lernfelt B, Landahl S, Palmertz B, Andreasson LA, Nilsson L, Persson G Odén A, and Svanborg A (1996) 15-year longitudinal study of blood pressure and dementia. Lancet 347:1141-1145.

Smith JK and Barron KW (1990) GABAergic responses in ventrolateral medulla in spontaneously hypertensive rats. Am J Physiol 258:R450-R456.

Stadler T, Veltmar A, Qadri F, and Unger T (1992) Angiotensin II evokes noradrenaline release from the paraventricular nucleus in conscious rats. Brain Res 569:117-122.

Steckelings UM, Kloet A, and Sumners C (2017) Centrally mediated cardiovascular actions of the angiotensin II Type 2 receptor. Trends Endocrinol Metab 28:684-693.

Stegbauer J, Vonend O, Habbel S, Quack I, Sellin L, Gross V, and Rump LC (2005) Angiotensin II modulates renal sympathetic neurotransmission through nitric oxide in AT2 receptor knockout mice. J Hypertens 23:1691-1698.
Stoll M, Steckelings UM, Paul M, Bottari SP, Metzger R, and Unger T (1995) The angiotensin AT2-receptor mediates inhibition of cell proliferation in coronary endothelial cells. J Clin Invest 95:651-657.

Stornetta RL, Hawelu-Johnson CL, Guyenet PG, and Lynch KR (1988) Astrocytes synthesize angiotensinogen in brain. Science 242:1444-1446.

Sumbalová Z, Kucharská J, and Kristek F (2010) Losartan improved respiratory function and coenzyme $\mathrm{Q}$ content in brain mitochondria of young spontaneously hypertensive rats. Cell Mol Neurobiol 30:751-758

Sumners C, Tang W, Zelezna B, and Raizada MK (1991) Angiotensin II receptor subtypes are coupled with distinct signal-transduction mechanisms in neurons and astrocytes from rat brain. Proc Natl Acad Sci USA 88:7567-7571.

Sun C, Zubcevic J, Polson JW, Potts JT, Diez-Freire C, Zhang Q, Paton JFR, and Raizada MK (2009) Shift to an involvement of phosphatidylinositol 3-kinase in angiotensin II actions on nucleus tractus solitarii neurons of the spontaneously hypertensive rat. Circ Res 105:1248-1255.

Sun J-C, Liu B, Zhang R-W, Jiao P-L, Tan X, Wang Y-K, and Wang W-Z (2018) Overexpression of $\beta$-arrestin 1 in the rostral ventrolateral medulla downregulates angiotensin receptor and lowers blood pressure in hypertension. Front Physiol 9:297. Szekeres M, Nádasy GL, Turu G, Soltész-Katona E, Tóth ZE, Balla A, Catt KJ, and Hunyady L (2012) Angiotensin II induces vascular endocannabinoid release, which attenuates its vasoconstrictor effect via CB1 cannabinoid receptors. $J$ Biol Chem 287:31540-31550.

Takane K, Hasegawa Y, Lin B, Koibuchi N, Cao C, Yokoo T, and Kim-Mitsuyama S (2017) Detrimental effects of centrally administered angiotensin II are enhanced in a mouse model of Alzheimer disease independently of blood pressure. $J$ Am Heart Assoc 6:e004897.

Takeuchi Y, Yamauchi K, Nakamura J, Shigematsu S, and Hashizume K (2006) Angiotensin II regulates migration in mouse cultured mesangial cells: evidence for the presence of receptor subtype-specific regulation. $J$ Endocrinol 191:361-367.

Tamura K, Umemura S, Nyui N, Yamakawa T, Yamaguchi S, Ishigami T, Tanaka S, Tanimoto K, Takagi N, Sekihara H, et al. (1996) Tissue-specific regulation of angiotensinogen gene expression in spontaneously hypertensive rats. Hypertension 27:1216-1223

Tang SS, Rogg H, Schumacher R, and Dzau VJ (1992) Characterization of nuclear angiotensin-II-binding sites in rat liver and comparison with plasma membrane receptors. Endocrinology 131:374-380.

Thoene-Reineke C, Rumschüssel K, Schmerbach K, Krikov M, Wengenmayer C, Godes M, Mueller S, Villringer A, Steckelings U, Namsolleck P, et al. (2011) Prevention and intervention studies with telmisartan, ramipril and their combination in different rat stroke models. PLoS One 6:e23646.

Tomassoni D, Avola R, Di Tullio MA, Sabbatini M, Vitaioli L, and Amenta F (2004) Increased expression of glial fibrillary acidic protein in the brain of spontaneously hypertensive rats. Clin Exp Hypertens 26:335-350.

Torika N, Asraf K, Cohen H, and Fleisher-Berkovich S (2017) Intranasal telmisartan ameliorates brain pathology in five familial Alzheimer's disease mice. Brain Behav Immun 64:80-90.

Tsuda K (2012) Renin-Angiotensin system and sympathetic neurotransmitter release in the central nervous system of hypertension. Int $J$ Hypertens 2012:474870.

Tzourio C (2007) Hypertension, cognitive decline, and dementia: an epidemiological perspective. Dialogues Clin Neurosci 9:61-70.

Ushio-Fukai M, Zafari AM, Fukui T, Ishizaka N, and Griendling KK (1996) p22phox is a critical component of the superoxide-generating NADH/NADPH oxidase system and regulates angiotensin II-induced hypertrophy in vascular smooth muscle cells. J Biol Chem 271:23317-23321.

Valenzuela R, Costa-Besada MA, Iglesias-Gonzalez J, Perez-Costas E, Villar-Cheda B, Garrido-Gil P, Melendez-Ferro M, Soto-Otero R, Lanciego JL, Henrion D, et al. (2016) Mitochondrial angiotensin receptors in dopaminergic neurons. Role in cell protection and aging-related vulnerability to neurodegeneration. Cell Death Dis 7: e2427.

Varagic J, Trask AJ, Jessup JA, Chappell MC, and Ferrario CM (2008) New angiotensins. J Mol Med (Berl) 86:663-671.

Veerasingham SJ and Raizada MK (2003) Brain renin-angiotensin system dysfunction in hypertension: recent advances and perspectives. $\mathrm{Br} J$ Pharmacol 139: 191-202.

Veerasingham SJ, Yamazato M, Berecek KH, Wyss JM, and Raizada MK (2005) Increased PI3-kinase in presympathetic brain areas of the spontaneously hypertensive rat. Circ Res 96:277-279.

Villapol S, Balarezo MG, Affram K, Saavedra JM, and Symes AJ (2015) Neurorestoration after traumatic brain injury through angiotensin II receptor blockage. Brain 138:3299-3315.

Villapol S and Saavedra JM (2015) Neuroprotective effects of angiotensin receptor blockers. Am $J$ Hypertens 28:289-299.

Villar-Cheda B, Costa-Besada MA, Valenzuela R, Perez-Costas E, Melendez-Ferro M, and Labandeira-Garcia JL (2017) The intracellular angiotensin system buffers deleterious effects of the extracellular paracrine system. Cell Death Dis 8:e3044.

Vital SA, Terao S, Nagai M, and Granger DN (2010) Mechanisms underlying the cerebral microvascular responses to angiotensin II-induced hypertension. Microcirculation 17:641-649.

Von Bohlen und Halbach O, Walther T, Bader M, and Albrecht D (2000) Interaction between Mas and the angiotensin AT1 receptor in the amygdala. $J$ Neurophysiol 83:2012-2021.

Waki H and Gouraud SS (2014) Brain inflammation in neurogenic hypertension. World J Hypertens 4:1-6.

Waki H, Gouraud SS, Maeda M, and Paton JF (2008) Specific inflammatory condition in nucleus tractus solitarii of the SHR: novel insight for neurogenic hypertension? Auton Neurosci 142:25-31.

Wang H-W, White R, Huang BS, Chen A, Ahmad M, and Leenen FH (2015) Both mineralocorticoid receptor and angiotensin II type 1 receptors in the subfornical organ mediate angiotensin II induced reactive oxygen species (ROS) in brain angiotensinergic pathways (Abstract). Hypertension 66 (Suppl 1):P192 
Wang K, Xu Y, Yang W, and Zhang Y (2017) Insufficient hypothalamic angiotensinconverting enzyme 2 is associated with hypertension in SHR rats. Oncotarget 8 20244-20251.

Wang Y, Li Y, Wu Y, Jia L, Wang J, Xie B, Hui M, and Du J (2014) 5 TNF- $\alpha$ and IL-1 $\beta$ neutralization ameliorates angiotensin II-induced cardiac damage in male mice. Endocrinology 155:2677-2687.

Warchol-Celinska E, Styczynska M, Prejbisz A, Przybylowska K, ChodakowskaZebrowska M, Kurjata P, Piotrowski W, Polakowska M, Kabat M, Zdrojewski T, et al. (2015) Hypertension in patients with Alzheimer's disease-prevalence, characteristics, and impact on clinical outcome. Experience of one neurology center in Poland. J Am Soc Hypertens 9:711-724.

Winklewski PJ, Radkowski M, Wszedybyl-Winklewska M, and Demkow U (2015) Brain inflammation and hypertension: the chicken or the egg? J Neuroinflammation 12:85.

Wright JW and Harding JW (2008) The angiotensin $\mathrm{AT}_{4}$ receptor subtype as a target for the treatment of memory dysfunction associated with Alzheimer's disease. $J$ Renin Angiotensin Aldosterone Syst 9:226-237.

Wright JW, Kawas LH, and Harding JW (2013) A role for the brain RAS in Alzheimer's and Parkinson's diseases. Front Endocrinol (Lausanne) 4:158.

Wright JW, Miller-Wing AV, Shaffer MJ, Higginson C, Wright DE, Hanesworth JM, and Harding JW (1993) Angiotensin II(3-8) (ANG IV) hippocampal binding: potential role in the facilitation of memory. Brain Res Bull 32:497-502.

Wu KL, Chan SH, and Chan JY (2012) Neuroinflammation and oxidative stress in rostral ventrolateral medulla contribute to neurogenic hypertension induced by systemic inflammation. $J$ Neuroinflammation 9:212.

Xiao L, Haack KKV, and Zucker IH (2013) Angiotensin II regulates ACE and ACE2 in neurons through p38 mitogen-activated protein kinase and extracellular signalregulated kinase 1/2 signaling. Am J Physiol Cell Physiol 304:C1073-C1079.

Yang H, Lu D, Vinson GP, and Raizada MK (1997) Involvement of MAP kinase in angiotensin II-induced phosphorylation and intracellular targeting of neuronal AT1 receptors. $J$ Neurosci 17:1660-1669.

Yang H, Lu D, Yu K, and Raizada MK (1996) Regulation of neuromodulatory actions of angiotensin II in the brain neurons by the Ras-dependent mitogen-activated protein kinase pathway. J Neurosci 16:4047-4058.

Yang H and Raizada MK (1998) MAP kinase-independent signaling in angiotensin II regulation of neuromodulation in SHR neurons. Hypertension 32:473-481.

Young CN and Davisson RL (2015) Angiotensin-II, the brain, and hypertension: an update. Hypertension 66:920-926.
Yun H-S, Park M-S, Ji E-S, Kim T-W, Ko I-G, Kim H-B, and Kim H (2014) Treadmill exercise ameliorates symptoms of attention deficit/hyperactivity disorder through reducing Purkinje cell loss and astrocytic reaction in spontaneous hypertensive rats. J Exerc Rehabil 10:22-30

Zanzinger $\mathrm{J}$ (2002) Mechanisms of action of nitric oxide in the brain stem: role of oxidative stress. Auton Neurosci 98:24-27.

Zhang M, Mao Y, Ramirez SH, Tuma RF, and Chabrashvili T (2010) Angiotensin II induced cerebral microvascular inflammation and increased blood-brain barrier permeability via oxidative stress. Neuroscience 171: $852-858$.

Zhong J, Basu R, Guo D, Chow FL, Byrns S, Schuster M, Loibner H, Wang XH, Penninger JM, Kassiri Z, et al. (2010) Angiotensin-converting enzyme 2 suppresses pathological hypertrophy, myocardial fibrosis, and cardiac dysfunction. Circulation 122:717-728, 18, 728.

Zhu DN, Moriguchi A, Mikami H, Higaki J, and Ogihara T (1998) Central amino acids mediate cardiovascular response to angiotensin II in the rat. Brain Res Bull 45:189-197.

Zhu M, Gelband CH, Posner P, and Sumners C (1999) Angiotensin II decreases neuronal delayed rectifier potassium current: role of calcium/calmodulindependent protein kinase II. J Neurophysiol 82:1560-1568.

Zhu T, Miller AG, Deliyanti D, Berka DR, Agrotis A, Campbell DJ, and WilkinsonBerka JL (2015) Prorenin stimulates a pro-angiogenic and pro-inflammatory response in retinal endothelial cells and an M1 phenotype in retinal microglia. Clin Exp Pharmacol Physiol 42:537-548.

Zimmerman MC, Lazartigues E, Lang JA, Sinnayah P, Ahmad IM, Spitz DR, and Davisson RL (2002) Superoxide mediates the actions of angiotensin II in the central nervous system. Circ Res 91:1038-1045.

Zimmerman MC, Lazartigues E, Sharma RV, and Davisson RL (2004) Hypertension caused by angiotensin II infusion involves increased superoxide production in the central nervous system. Circ Res 95:210-216.

Address correspondence to: Dr. Michelle A. Clark, College of Pharmacy, Department of Pharmaceutical Sciences, Nova Southeastern University, 3200 South University Dr., Fort Lauderdale, FL 33328. E-mail: miclark@ nova.edu 